VIVIAN DE ALVARENGA GUEDES

\title{
EFEITOS INIBITÓRIOS DE UMA PISTA VISUAL EM TAREFAS DE TEMPO DE REAÇÃO
}

Dissertação apresentada ao Instituto de Ciências Biomédicas da Universidade de São Paulo, para obtenção do Título de Mestre em Ciências (Fisiologia Humana)

São Paulo

2007 
VIVIAN DE ALVARENGA GUEDES

\section{EFEITOS INIBITÓRIOS DE UMA PISTA VISUAL EM TAREFAS DE TEMPO DE REAÇÃO}

Dissertação de Mestrado apresentada ao Instituto de Ciências Biomédicas da Universidade de São Paulo, para obtenção do Título de Mestre em Ciências (Fisiologia Humana)

Área de concentração: Fisiologia Humana

Orientador: Prof. Dr. Luiz Eduardo Ribeiro do Valle 


\section{DEDICATÓRIA}

A Valério Marques 


\section{AGRADECIMENTOS}

Agradeço ao Prof. Dr Luiz Eduardo Ribeiro do Valle, meu orientador, pela imensa dedicação aos seus alunos e por me inspirar com o seu amor e seu respeito pela ciência.

Aos professores Marcus Vinícius C. Baldo, Luiz Augusto Teixeira e Gilberto Xavier, pelas sugestões dadas no exame de qualificação.

Aos colegas de laboratório, pelo companheirismo, pelas risadas, pelo incentivo e pela amizade.

Aos demais amigos, por acreditarem em mim.

A toda a minha família, que não me deixa esquecer de minhas origens e que, lá longe, entende minha ausência, mesmo sem compreender minhas escolhas.

A valério Marques, pelo amor e apoio incondicionais.

Aos voluntários deste trabalho e à Capes pelo apoio financeiro. 


\section{RESUMO}

GUEDES, V. A. Efeitos inibitórios de uma pista visual em tarefas de tempo de reação. 2007. 80f. Dissertação (Mestrado em Fisiologia Humana) - Instituto de Ciências Biomédicas, Universidade de São Paulo, São Paulo, 2007.

Agir de modo apropriado em um ambiente complexo e dinâmico requer pelo menos três estágios de processmento da infomação externa: um estágio sensorial, um decional e um motor. Em tarefas de tempo de reação, uma pista visual pode engatilhar diversos processos, que facitam ou inibem diferentes estágios do processamento do estímulo-alvo. Em experimentos envolvendo uma tarefa de discriminação vai/não-vai com estímulos centrais, um efeito inibitório da pista foi observado quando um único valor de assincronia entre o início dos estímulo (SOA) foi usado, mas não o valor de SOA foi variado. Em uma tarefa de discriminação de escolha, nenhum efeito inibitório da pista foi observado, enquanto na tarefa de detecção foi encontrada uma facilitação. Nossos resultados sugerem que o nível de preparação motora é importante para o efeito inibitório da pista encontrado neste estudo. Nós propomos que esses efeitos inibitórios surgem de uma inibição de uma tendência automática de responder à pista. Como consequência, a resposta ao estimulo-alvo subsequente fica mais lenta. Nossos dados sugerem que mecanismos decisionais contribuem para os efeitos inibitórios da pista relatados na literatura sobre inibição de retorno.

Palavras-chave: atenção visuoespacial, atenção temporal, preparação motora, inibição de retorno. 


\begin{abstract}
GUEDES, V. A. Inhibitory effects of a visual cue in reaction time tasks. 2007. 100F Master Thesis (Human Pshisiology) - Instituto de Ciências Biomédicas, Universidade de São Paulo, São Paulo, 2007.

Acting properly in a complex and changing environment requires at least three processing stages of the external information: a sensory, a decisional and a motor stage. In reaction time tasks, a visual cue elicits specific modulation of these processes out coming either a facilitatory or inhibitory influence on manual reaction time. In experiments involving a go/no-go discrimination task with central stimuli, an inhibitory cueing effect on reaction time was found when a fixed asynchrony between cue onset and target onset (SOA) was used, but not when the SOA was varied. In a choice discrimination task, no inhibitory cueing effect was observed, while in a detection task we found a facilitatory cueing effect. Take together our results suggest that the motor preparation level is important for the inhibitory cueing effect found in the present study. We propose that inhibitory cueing effect arises from the inhibition of an automatic tendency to respond to the cue. As a consequence, the response to the subsequent target stimulus is also decelerated. Our data support the decisional theory for the inhibitory cueing effects reported in the literature about inhibition of return.
\end{abstract}

Key words: visuospatial attention, temporal attention, motor preparation, inhibition of return. 


\section{LISTA DE ILUSTRAÇÕES}

Figura 3.1 - Foto da vista lateral da sala de experimentos .20

Figura 3.2 - Representação esquemática da seqüência de aparecimento dos estímulos. .22

Figura 3.3 - Representação esquemática do padrão temporal da apresentação dos estímulos. .22

Figura 3.4 - Tempo de reação em milisegundos (média \pm e.p.m.)...............................................25

Figura 4.1 - Representação esquemática da seqüência de aparecimento dos estímulos .............27

Figura 4.2 - Representação esquemática do padrão temporal da apresentação dos

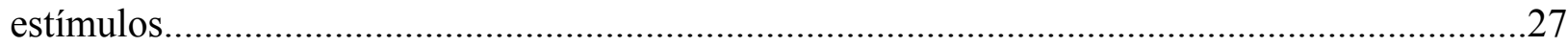

Figura 4.3 - Tempo de reação em milisegundos (média \pm e.p.m.)..............................................28

Figura 5.1 - Representação esquemática da seqüência de aparecimento dos estímulos ..............32

Figura 5.2 - Representação esquemática do padrão temporal da apresentação dos

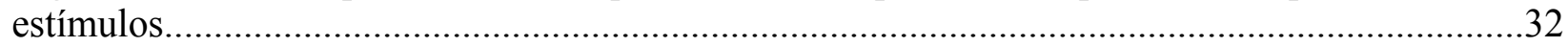

Figura 5.3 - Tempo de reação em milisegundos (média \pm e.p.m.)..................................................34

Figura 6.1 - Representação esquemática da seqüência de aparecimento dos estímulos.............38

Figura 6.2 - Representação esquemática do padrão temporal da apresentação dos estímulos

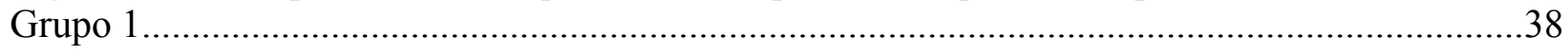

Figura 6.3 - Representação esquemática do padrão temporal da apresentação dos estímulos

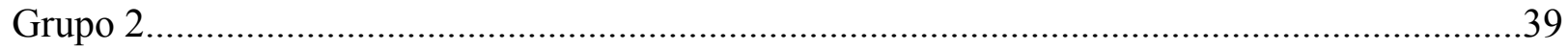

Figura 7.1 -Representação esquemática da seqüência de aparecimento dos estímulos 40

Figura 7.2 - Representação esquemática do padrão temporal da apresentação dos estímulos. 40

Figura 7.3 - Tempo de reação em milisegundos (média \pm e.p.m.).................................................45

Figura 8.1 - Representação esquemática da seqüência de aparecimento dos estímulos 47

Figura 8.2 - Representação esquemática do padrão temporal da apresentação dos estímulos. 47

Figura 8.3 - Tempo de reação em milisegundos (média \pm e.p.m.). .48 


\section{SUMÁRIO}

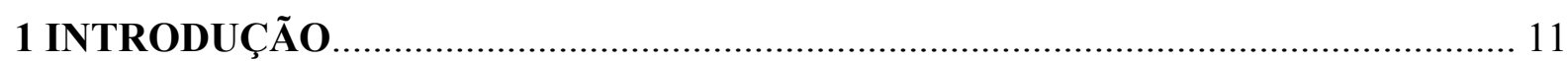

3 OBJETIVOS

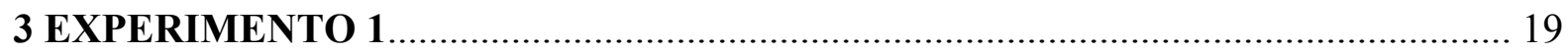

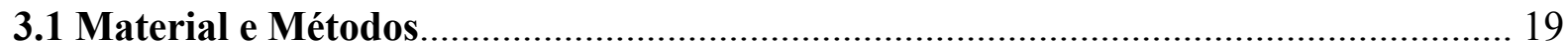

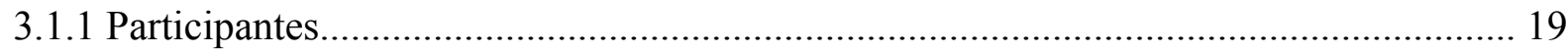

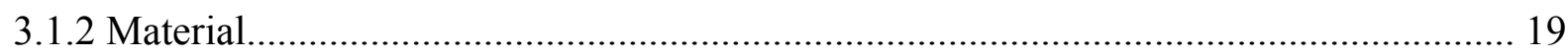

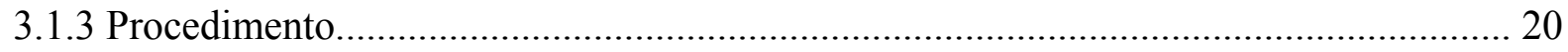

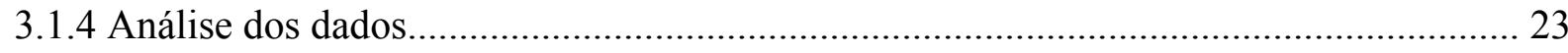

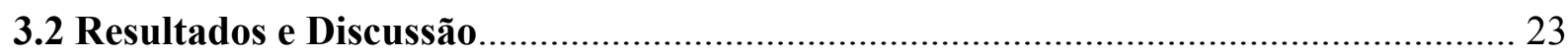

3.2.1 Tempo de Reação................................................................................................ 24

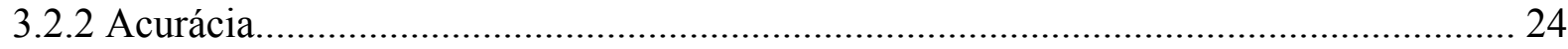

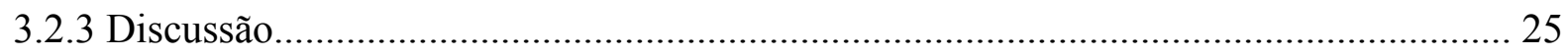

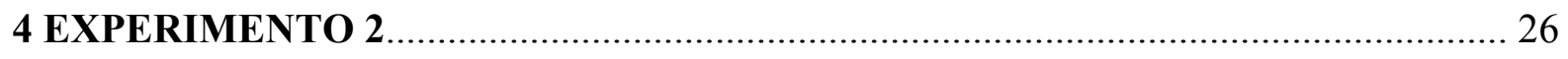

4.1 Material e Métodos............................................................................................... 26

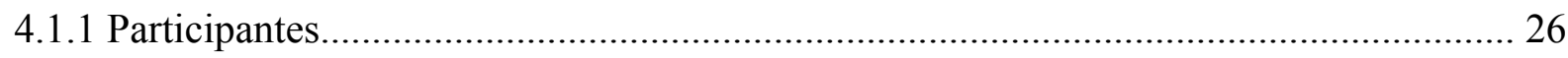

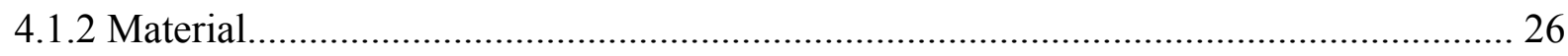

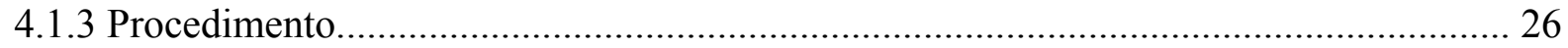

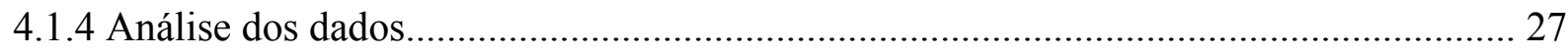

4.2 Resultados e Discussão

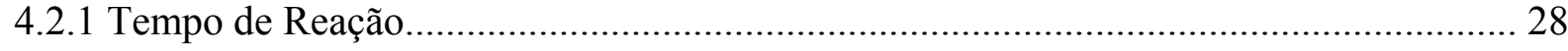

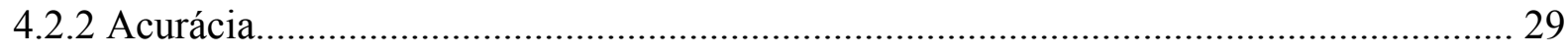

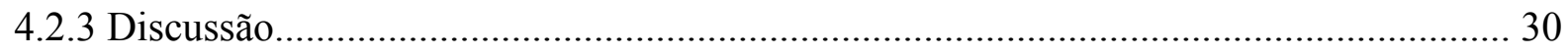

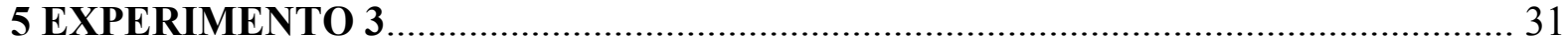

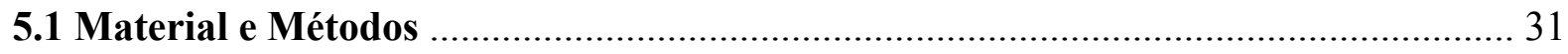

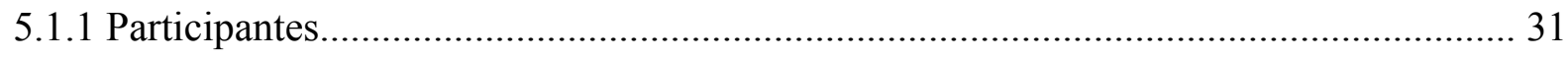

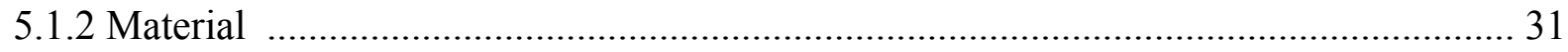

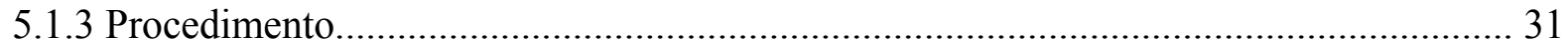

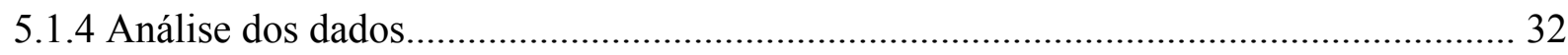

5.2 Resultados e Discussão 


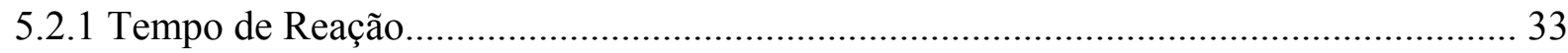

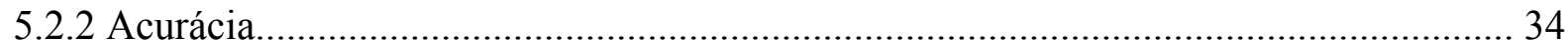

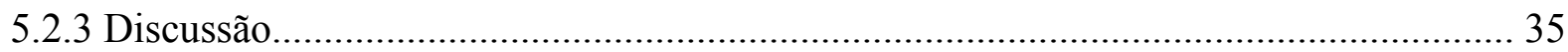

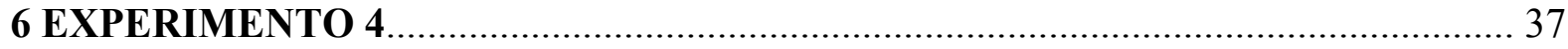

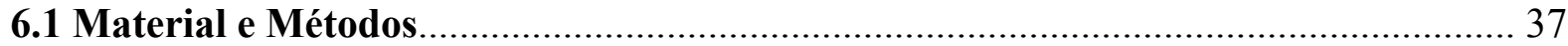

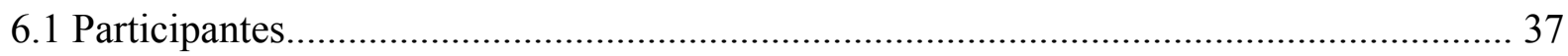

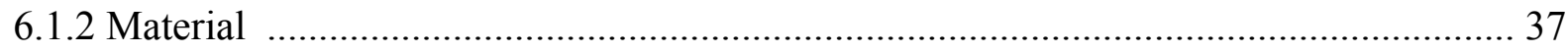

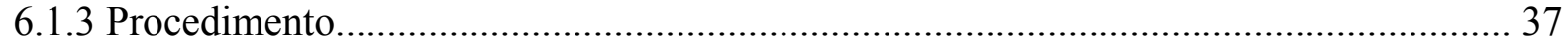

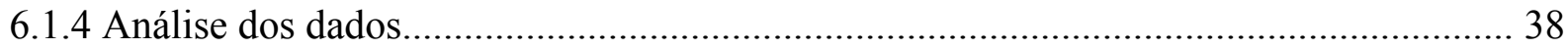

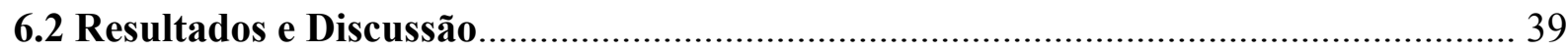

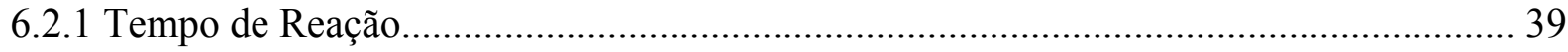

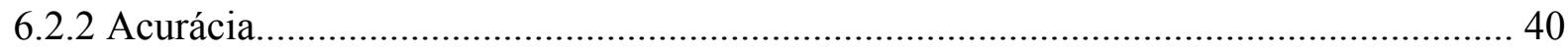

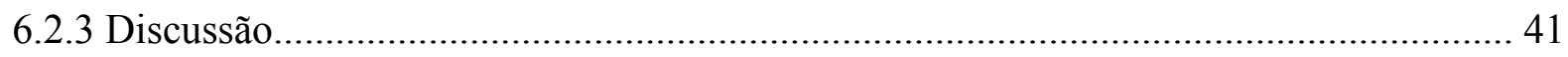

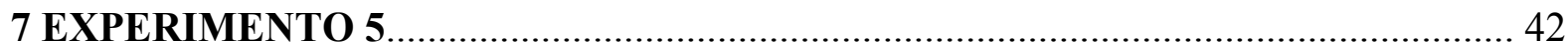

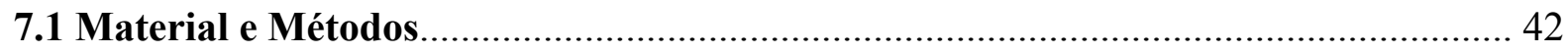

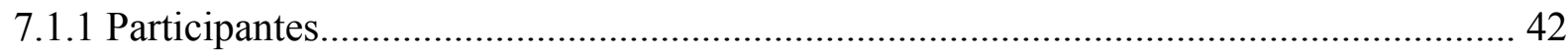

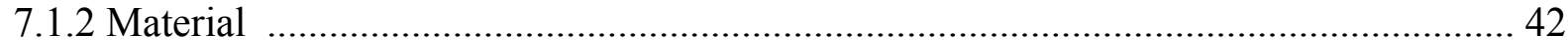

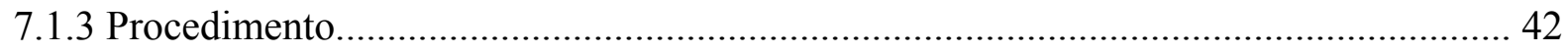

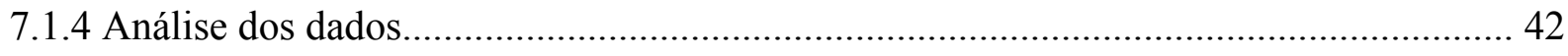

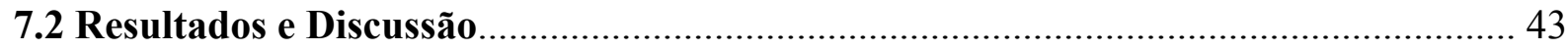

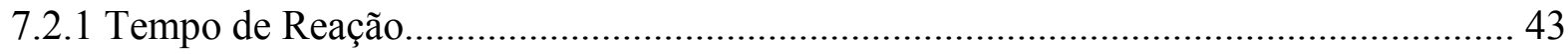

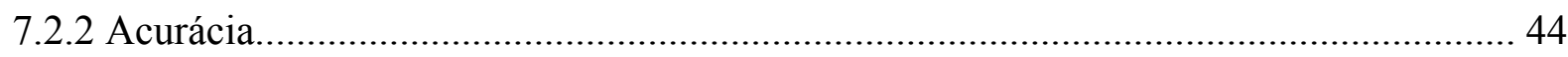

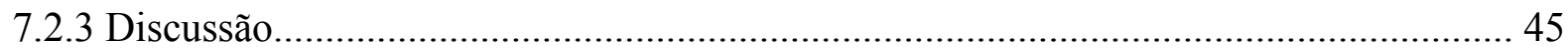

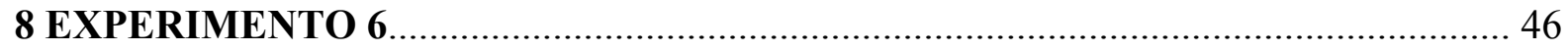

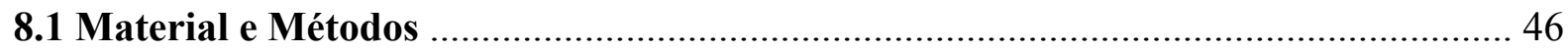

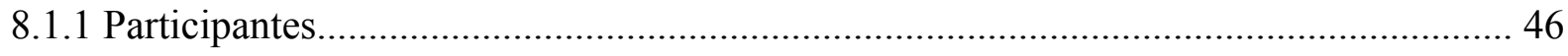

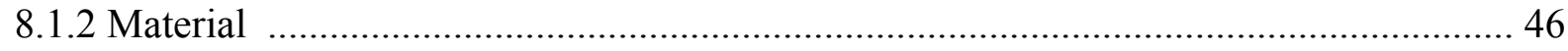

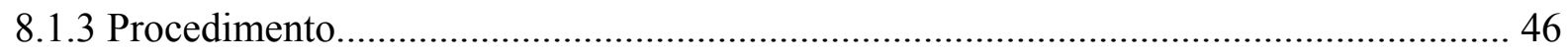

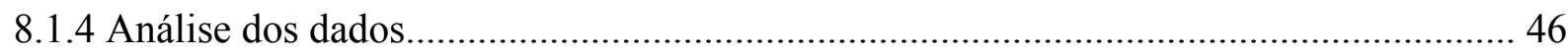

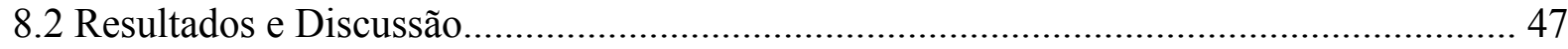

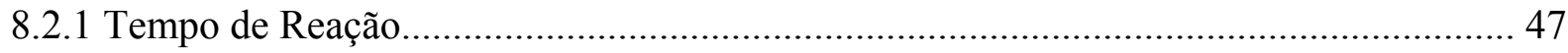




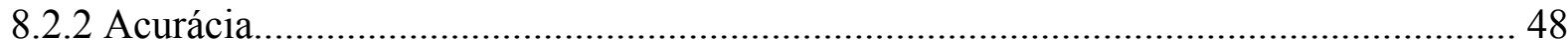

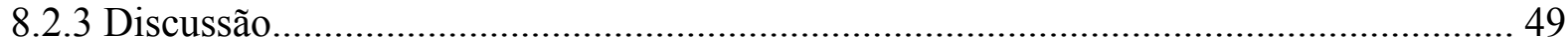

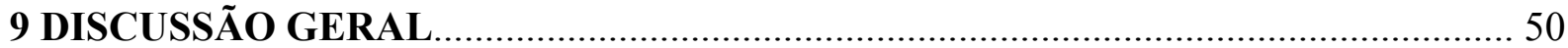

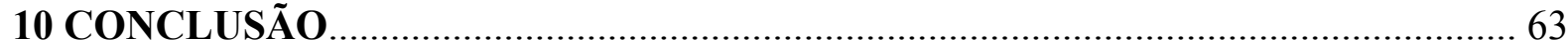

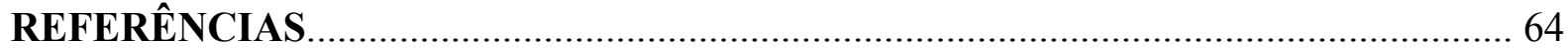




\section{INTRODUÇÃO}

Interagir de forma coerente e adaptativa com um ambiente complexo e dinâmico depende da escolha do comportamento mais apropriado em cada situação. A transformação de representações internas do contexto ambiental em ações voluntárias envolve diversos mecanismos flexíveis e pelo menos três estágios de processamento da informação: um estágio sensorial, um decisional e um motor.

O estágio sensorial diz respeito ao processamento das diferentes formas de energia que chegam aos receptores na superfície do corpo, de modo que se tornem informação para o organismo. O estágio motor se refere à execução do comportamento propriamente dito, ou seja, envolve o comando para a contração coordenada dos grupos musculares necessários à realização da ação. Por fim, o estágio decisional envolve a escolha da resposta mais apropriada em relação às informações ambientais, com base no contexto e na experiência prévia. No processo de decisão, as informações sensoriais são interpretadas, integradas com a expectativa de recompensa e com as informações cognitivas (COURTNEY, 2004; DECO e ROLLS, 2005; FUNAHASHI, 2001; FUSTER, 2000; FUSTER 2004; OPRIS e BRUCE, 2005). Quando um estímulo relevante para a ação é identificado, a resposta mais apropriada deve ainda ser selecionada e só então executada.

O comportamento humano envolve processos preparatórios, ajustes que maximizam o processamento das informações relevantes e a resposta a elas. A experiência prévia, as informações cognitivas e as pistas ambientais são usadas para antecipar eventos futuros. A probabilidade de ocorrência de um evento de interesse ou a freqüência com que relações de tempo e espaço entre estímulos sensoriais se repetem geram expectativas em relação ao ambiente (GÓMEZ et al., 2005). De acordo com o contexto, configurações cognitivas são estabelecidas para lidar com as demandas da tarefa, definindo as regras através das quais os estímulos sensoriais e as respostas motoras são selecionadas (ARNOTT et al., 2001; RUSHWORTH et al., 2005; RUSHWORTH et al., 2002).

A expectativa em relação a probabilidade de ocorrência de um evento poderia gerar um viés, que seria uma tendência a favorecer uma resposta em relação a outra. Um viés pode ser estabelecido por meio de mudanças no critério. Quanto maior o critério, maior a quantidade de evidências sensoriais que devem ser acumuladas para que uma resposta ocorra.

O comportamento adaptativo depende de diversos mecanismos de seleção. O sistema 
nervoso não pode processar por completo toda a informação proveniente do ambiente e nem responder a todo estímulo que processa. Quando a decisão de responder a determinado estímulo é tomada, apenas a opção de resposta com maior peso ou "saliência" face às informações disponíveis é selecionada (OPRIS e BRUCE, 2005). Da mesma forma, os vários estímulos do campo visual interagem de modo competitivo (DECO e ROLLS, 2005; DESIMONE e DUNCAN, 1995). O processo que culmina na seleção da informação comportamentalmente relevante em dado momento para um processamento preferencial recebe o nome de atenção (COURTNEY, 2004; LUPIÁÑEZ et al, 1997; LUPIÁÑEZ e RUZ, 2002; HAN et al., 2006; OPFINGER et al., 2000; POSNER, 1980). A atenção pode ser orientada para locais do espaço, objetos ou para características isoladas, como uma cor (KLEIN, 2000; YANTIS, et al. 2003).

A orientação da atenção pode ocorrer de forma voluntária ou automática. A orientação automática ou exógena da atenção ocorre em resposta a estímulos que se destacam por serem discrepantes do contexto em que se inserem, como uma flor vermelha entre outras amarelas ou um grito em um local silencioso. A orientação voluntária ou endógena da atenção ocorre em função dos objetivos do observador (JONIDES, 1981; LAMBERT e HOCKEY, 1991; POSNER, 1978; POSNER, 1980; THEEUWES, 1991). A orientação da atenção aumenta a qualidade e a intensidade com que as informações ambientais são processadas e influencia mecanismos decisionais e motores (CORBETA e SHULMAN, 2002; DESIMONE e DUNCAN, 1995; DRIVER e FRITH, 2000; REYNOLDS et al., 2000; YANTIS e SERENCES, 2003).

Além disso, os termos intenção, atenção motora e atenção para a ação são utilizados para designar a habilidade de se focar em certas respostas ou em regras de seleção estímulo-resposta específicas (RUSHWORTH et al., 2002; RUSHWORTH et al., 2005). Por fim, da mesma forma que conhecer a localização de um evento de interesse torna o comportamento mais eficiente, a expectativa em relação a quando um evento ocorrerá pode melhorar as respostas comportamentais. Quando os recursos atencionais são direcionados para um determinado momento, ao invés de um determinado local, ocorre a orientação da atenção no tempo (CORREA et al., 2004; CORREA et al., 2006; COULL et al., 1998). Esse processo pode modular processos decisionais e motores ou mesmo o processamento visual precoce (CORREA et al., 2006).

O comportamento pode ser estudado pela medida da latência de uma resposta associada a um estímulo sensorial denominado estímulo-alvo. Nesse tipo de estudo, o número de estímulos e suas características, a relação de tempo e espaço entre eles, assim como as respostas requeridas, 
podem ser variados conforme os objetivos do pesquisador. O tempo decorrido entre a apresentação do estímulo-alvo e a execução de uma resposta motora associada a ele é denominado tempo de reação.

Antes da apresentação do estímulo-alvo, um outro estímulo visual denominado pista pode ser apresentado. A pista pode engatilhar processos em diferentes estágios de processamento e afetar simultaneamente diferentes mecanismos, facilitando alguns e inibindo outros (LUPIÁÑEZ et al., 2005). O efeito comportamental da apresentação da pista, ou seja, a redução ou o aumento do tempo de reação, dependerá do balanço entre esses diferentes processos.

A pista pode interferir diretamente no processamento sensorial do estímulo-alvo. Este é o caso de um fenômeno denominado mascaramento. O mascaramento visual se refere a uma redução da visibilidade de um estímulo pela presença de um segundo estímulo próximo no tempo e no espaço (ENNS e DI LOLLO, 2000). Quando o estímulo mascarador vem antes do estímulo mascarado ocorre o chamado mascaramento anterógrado. Se a ordem dos estímulos se inverte e o estímulo mascarado vem antes, ocorre o mascaramento retrógrado (BACKMAN, 1989; BREITMEYER, 1984). O mascaramento não se trata de um fenômeno unitário. Sua manifestação varia de acordo com os parâmetros da tarefa e na sua origem há componentes periféricos, na retina, e centrais, no córtex visual primário (BACKMAN, 1989; BREITMEYER, 1984).

O mascaramento apresenta um papel importante no estudo das propriedades espacias e temporais da percepção visual (BREITMEYER, 1984). Na maioria dos estudos recentes sobre visão, o mascaramento aparece como uma maneira de controlar a dificuldade sensorial da tarefa (ENNS e DI LOLLO, 2000). Esse fenômeno tem sido ainda abordado no estudo de processos cognitivos de alta ordem como a consciência e de anormalidades clínicas como dislexia, mania e esquizofrenia (BREITMEYER e OGMEN, 2000).

A apresentação da pista pode afetar o processamento sensorial do estímulo-alvo também indiretamente, através de mecanismos atencionais. O efeito da orientação da atenção no processamento de um estímulo-alvo foi quantificado pela primeira vez por Posner e Cohen (1984) com um desenho experimental cujos elementos básicos são ainda hoje bastante utilizados. A metodologia consiste na apresentação de dois breves estímulos visuais em seqüência, a pista e o estímulo-alvo, na periferia do campo visual. Os estímulos podem ser apresentados no mesmo local ou em posições opostas e o intervalo de tempo entre eles pode ser variado.

Com um intervalo entre o início dos estímulos de até 150 ms, Posner e Cohen (1984) 
observaram que o tempo de reação era menor quando pista e estímulo-alvo apareciam na mesma posição em relação a quando eram apresentados em posições opostas. Esse efeito foi denominado facilitação e atribuído à orientação da atenção para o local de aparecimento da pista. No entanto, o resultado oposto foi observado com um intervalo entre o início dos estímulos maior que 250 ms. Esse efeito inibitório da apresentação da pista recebeu o nome de inibição do retorno.

A inibição de retorno teria uma importância estratégica na maximização da exploração do ambiente (KLEIN, 2000). Com longos intervalos entre o início dos estímulos (acima de 250 ms), a atenção já teria se deslocado do local da pista. Sendo assim, a inibição de retorno seria a manifestação comportamental de um processo inibitório que preveniria a reorientação da atenção para uma determinada posição do espaço. Em função desse seu valor ecológico e da possibilidade de entender melhor a atenção através de seu estudo, esse fenômeno despertou grande interesse nas últimas décadas.

Inicialmente, acreditava-se que os efeitos da pista na orientação exógena da atenção teriam um curso temporal invariável (LUPIÁÑEZ et al., 2007), ou seja, em qualquer tarefa haveria facilitação precoce seguida de inibição de retorno. Além disso, diversos estudos sugerem que a atenção e a inibição de retorno são similarmente afetadas pela modalidade e intensidade do estímulo-alvo, além do tipo de resposta solicitado na tarefa (RUTER-LORENZ et al., 1996); a facilitação não necessariamente é observada (LAMBERT e HOCKEY, 1991; LUPIÁÑEZ et al., 2001, SAMUEL e KAT, 2003; TASSINARI et. al., 1994) e a inibição de retorno pode se manifestar muito precocemente (LUPIÁÑEZ et al., 2001, VAN DER LUBBE et al., 2006). A inibição de retorno foi ainda descrita para tarefas de discriminação que não envolviam os atributos espaciais dos estímulos, como cor (LUPIÁÑEZ et al., 2007; PRATT et al., 2001) e entre modalidades sensoriais (KLEIN, 2000).

Os resultados atribuídos à inibição de retorno são tão variados que levam a supor que mais de um mecanismo esteja envolvido com esse fenômeno. Na verdade, grande parte dos trabalhos realizados desde a descrição da inibição de retorno visou à identificação de suas causas. A proposta de que mecanismos atencionais estariam envolvidos com a inibição de retorno recebeu considerável suporte ao longo do tempo (CASTEL et al., 2005; LUPIÁÑEZ et al., 2007; PRIME e WARD, 2004). Entretanto, diversos outros mecanismos foram também propostos para explicá-la (KLEIN, 2000; TAYLOR e KLEIN, 1998).

Klein e Taylor (1994) propuseram que a inibição de retorno resultaria de um viés em 
favor de respostas dirigidas a novos locais do espaço e poderia surgir em um mapa motor espacial que direciona a ação. Portanto, a inibição de retorno envolveria mecanismos decisionais, o que foi apoiado por diversos estudos subseqüentes (IVANOFF e KLEIN, 2001; IVANOFF e KLEIN 2002; IVANOFF e KLEIN 2004; VAN DER LUBBE et al., 2005; VAN DER LUBBE et al., 2006). Não há consenso a respeito dos mecanismos que estariam subjacentes a essa inibição. Um mecanismo decisional e um atencional não seriam mutuamente exclusivos. Os resultados comportamentais poderiam refletir uma combinação de ambos, sendo que o peso de cada um deles dependeria das demandas da tarefa.

A inibição de retorno surge tipicamente mais cedo em tarefas de detecção que de discriminação (KLEIN, 2000; LUPIÁÑEZ et al., 1997; LUPIÁÑEZ et al., 2001). Diferentes tipos de tarefas apresentam demandas perceptuais e motoras distintas. Nas tarefas de detecção, não há necessidade de identificação do estímulo-alvo para a execução da resposta. Ao contrário, nas tarefas de discriminação, os estímulos devem ser processados até sua identificação para que a resposta apropriada ocorra. Nas tarefas de discriminação vai/não-vai, uma resposta deve ser executada para um estímulo-alvo e inibida para outro, enquanto nas tarefas de discriminação de escolha, a resposta é dada com a mão esquerda para um estímulo-alvo e com a mão direita para outro. Sendo assim, nas tarefas de discriminação haveria uma maior demanda perceptual. Por isso, a orientação da atenção para a posição da pista ocorreria com maior intensidade (KLEIN, 2000) e/ou a atenção permaneceria por mais tempo no local da pista (LUPIÁÑEZ et al., 2001) nas tarefas de discriminação que nas tarefas de detecção, o que levaria a um atraso no surgimento da inibição de retorno nesse primeiro tipo de tarefa.

As tarefas de deteç̧ão e de discriminação diferem ainda quanto ao nível de preparação motora. Preparação motora seria um estado de prontidão específico que precede um movimento e compreenderia a seleção da resposta e a sua subseqüente programação (KLAPP, 1995). Nas tarefas de detecção e nas tarefas de discriminação vai/não-vai, existe apenas uma resposta possível, que estaria selecionada e programada antes do aparecimento do estímulo-alvo. Nas tarefas de discriminação de escolha, a resposta só pode ser preparada após a identificação do estímulo-alvo.

Segundo Van der Lubbe et al. (2005), essa diferença no nível de preparação motora seria a causa da diferença no momento de início da inibição de retorno entre tarefas de detecção e de discriminação. Segundo a proposta de Van der Lubbe et al. (2005), o elevado 
nível de preparação motora nas tarefas de detecção poderia acelerar o aparecimento de um processo inibitório em mecanismos decisionais. Outra possibilidade seria que com um alto nível de preparação motora, qualquer estímulo que aparecesse na tela, inclusive a pista, poderia ser desencadear uma resposta (VAN DER LUBBE et al., 2006). A inibição da resposta à pista poderia afetar a resposta ao estímulo-alvo, aumentando o tempo de reação a ele.

A inibição de retorno foi primeiramente descrita para a dimensão do espaço (FRANCIS e MILLIKEN, 2003). Por isso, a maioria dos estudos sobre inibição de retorno envolvem estímulos periféricos. No entanto, efeitos inibitórios da pista com estímulos apresentados no centro do campo visual também foram descritos na literatura da área (IVANOFF e KLEIN, 2001; MAYLOR e HOCKEY, 1985). Nesse caso, o efeito inibitório da pista não poderia se dever a uma inibição do retorno da atenção a um local do espaço, já que a atenção permanece sempre na mesma posição. Ivanoff e Klein (2001) observaram essa inibição com estímulos centrais em uma tarefa vai/não-vai e propuseram que ela estaria relacionada a alterações no critério de resposta, sendo causada por mecanismos parcialmente diferentes daqueles envolvidos na inibição periférica.

A influência das características da tarefa em mecanismos atencionais tem sido amplamente discutida na literatura (KLEIN, 2000; LUPIÁÑEZ et al., 1997; LUPIÁÑEZ et al., 2001). Entretanto, muito pouco se sabe a respeito dos fatores envolvidos com o surgimento de processos inibitórios no estágio de decisão. Estudar os efeitos inibitórios da pista com estímulos apresentados no centro da tela seria uma forma de entender melhor tais processos, já que os efeitos da orientação exógena da atenção seriam minimizados e, consequentemente, a interferência de mecanismos atencionais.

Em trabalhos anteriores de nosso laboratório, Fuga (2002) observou um efeito inibitório da pista em uma tarefa vai/não-vai com estímulos centrais e um intervalo entre o início dos estímulos sempre de $100 \mathrm{~ms}$. O intervalo de tempo constante entre os estímulos possibilita que a pista sinalize o momento de aparecimento do estímulo-alvo. Conhecer quando aparecerá o evento de interesse, aumentaria o nível de preparação motora, que foi associado ao aparecimento precoce da inibição de retorno em tarefas de detecção com estímulos periféricos (VAN DER LUBBE et al., 2005; VAN DER LUBBE et al., 2006). O 
processo inibitório desencadeado pela pista na tarefa usada por Fuga (2002), poderia estar relacionado a mecanismos semelhantes.

Sendo assim, neste trabalho, investigamos os mecanismos envolvidos com o aparecimento de um efeito inibitório da pista em uma tarefa de tempo de reação vai/não-vai e o quanto ele depende do alto grau de preparação motora.

Além disso, investigamos se o efeito inibitório da pista sobre o processamento de dois diferentes estímulos-alvo, a linha e a cruz. Com isso, nosso trabalho poderia ajudar a esclarecer os resultados de um estudo anterior de nosso laboratório (AZEVEDO et al., 2001). Esses autores observaram que em uma tarefa de tempo de reação vai/não-vai em que os estímulos eram apresentados na periferia do campo visual, a pista causava uma facilitação quando o estímuloalvo era um linha no interior de um anel, mas não exercia qualquer efeito significativo no tempo de reação quando o estímulo-alvo era uma cruz no interior de um anel. Azevedo et al. (2001) propuseram que a pista provocou um mascaramento anterógrado da cruz, que teria antagonizado os efeitos da orientação da atenção. Por isso, a facilitação apareceu apenas para a linha. Uma outra possibilidade seria considerar que a cruz é mais discriminável que a linha. Essa diferença na discriminabilidade afetaria a magnitude da orientação da atenção, causando os diferentes efeitos da pista. 
2 OBJETIVOS

\subsection{Objetivo Principal}

Determinar os mecanismos responsáveis pelos efeitos inibitórios da pista visual no processamento do estímulo-alvo visual em uma tarefa de tempo de reação vai/não-vai.

\subsection{Objetivos Secundários}

- Determinar a importância do grau de preparação motora para a observação dos efeitos inibitórios da pista.

- Determinar as causas de possíveis diferenças no efeito da pista no processamento de estímulos-alvo diferentes. 



\section{EXPERIMENTO 1}

Neste experimento, utilizamos uma tarefa vai/não-vai com estímulos centrais e um intervalo entre o início dos estímulos de $100 \mathrm{~ms}$. Se um efeito inibitório da pista fosse observado nessa tarefa, investigaríamos os mecanismos subjacentes a ele.

Além disso, procuramos possíveis diferenças no efeito da pista no processamento da linha e da cruz.

\subsection{Material e Métodos}

\subsubsection{Participantes}

Foram selecionados 16 voluntários, de ambos os sexos, estudantes de graduação ou pós-graduação da Universidade de São Paulo, destros, que não utilizassem medicamentos com ação no sistema nervoso central, com visão normal ou corrigida, sem experiência prévia em testes semelhantes e que não cometessem mais de $10 \%$ de erros na tarefa. Este projeto de pesquisa foi aprovado pela Comissão de Ética em Pesquisa em Seres Humanos do Instituto de Ciências Biomédicas da Universidade de São Paulo.

\subsubsection{Material}

Os testes foram realizados em uma sala ventilada, com revestimento acústico e baixa iluminação (Vide figura 3.1). Os voluntários permaneciam sentados em frente a um computador com seus olhos a uma distância de $57 \mathrm{~cm}$ da tela, com a cabeça posicionada em um apoiador de fronte e mento. A tela na qual eram apresentados os estímulos tinha luminância de $0,01 \mathrm{~cd} / \mathrm{m}^{3}$. Os voluntários respondiam aos estímulos apertando uma tecla com o dedo indicador direito. As respostas foram registradas e o tempo de reação calculado por um microcomputador PC/AT 486 e um programa elaborado com um aplicativo "Micro experimental Laboratory - MEL2 (MEL Professional 2.01- Psychology Software Tools, Inc)". A precisão das medidas do tempo de reação foi de $1 \mathrm{~ms}$. 


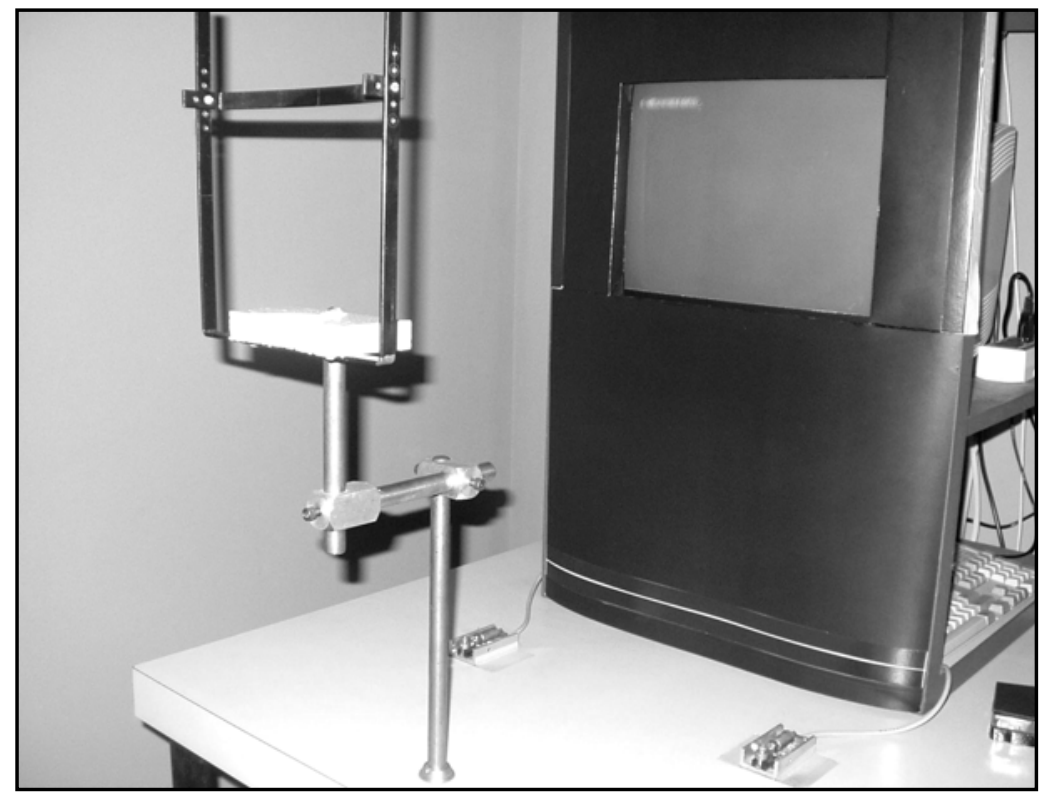

Figura 3.1 - Foto da vista lateral da sala de experimentos.

\subsubsection{Procedimento}

Os voluntários realizaram duas sessões de testes, com duração aproximada de 30 minutos cada, separadas por no máximo sete dias. A primeira sessão teve como objetivo familiarizar o voluntário com as condições experimentais e seus resultados não foram analisados.

Cada sessão era constituída por quatro blocos de tentativas. Os blocos eram separados por intervalos de pelo menos $15 \mathrm{~s}$, reduzindo dessa forma um eventual cansaço dos voluntários. Cada bloco devia conter 64 tentativas corretas. As tentativas em que houve erros eram repostas automaticamente em cada bloco. Isto possibilitou que todos os participantes tivessem o mesmo número de tentativas válidas registradas por condição experimental.

Antes de cada sessão, os voluntários receberam instruções por escrito (Anexo D), reforçadas verbalmente no interior da sala de testes. Além disso, os voluntários realizavam um breve treino de cerca de 20 tentativas, que não eram registradas. Este treino era acompanhado pelo pesquisador a fim de esclarecer possíveis dúvidas.

Os voluntários eram submetidos ainda a um teste de acuidade visual, a um teste de dominância ocular e a uma avaliação da dominância manual (OLDFIELD, 1971) ao final da segunda sessão. Um termo de consentimento era assinado no final da primeira sessão. Vide 
Anexos.

Desde o início de cada tentativa, aparecia um anel de $1,76^{\circ}$ de diâmetro localizado no centro da tela, com um ponto de fixação em seu interior. Na primeira sessão, entre $1750 \mathrm{e}$ $2250 \mathrm{~ms}$ após seu aparecimento o ponto de fixação se apagava. Após $100 \mathrm{~ms}$, em todas as tentativas era apresentado no interior do anel um estímulo-alvo.

A tarefa consistia em apertar uma tecla com o dedo indicador direito quando era apresentado o estímulo-alvo positivo e não responder quando aparecia o estímulo-alvo negativo. Tanto o estímulo-alvo positivo quanto o estímulo-alvo negativo eram apresentados em metade das tentativas. Os voluntários eram divididos em dois grupo de oito integrantes, de modo que em um deles o estímulo-alvo positivo era uma linha vertical e no outro era uma cruz. Em ambos os grupos o estímulo-alvo negativo era o anel. As dimensões da linha vertical e de cada um dos braços da cruz eram $0,96^{\circ}$ de comprimento e $0,04^{\circ}$ de largura. $\mathrm{O}$ diâmetro do anel era $0,29^{\circ}$. Todos os estímulos-alvo eram brancos, tinham luminância de $25,8 \mathrm{~cd} / \mathrm{m}^{2}$ e duravam $50 \mathrm{~ms}$.

$\mathrm{Na}$ segunda sessão, o estímulo-alvo podia ser precedido por outro estímulo visual denominado pista. A pista consistia no aumento do brilho do anel, durava $100 \mathrm{~ms}$ e aparecia em $50 \%$ das tentativas. Todos os estímulos eram apresentados centralmente. A assincronia entre o início dos estímulos ou SOA (Sigla em inglês para stimulus onset asynchrony) era sempre de $100 \mathrm{~ms}$. O intervalo entre o fim da pista e o início do estímulo-alvo era sempre zero. As relações espaciais e temporais entre os estímulos estão representadas nas figuras $3.2 \mathrm{e}$ 3.3.

$\mathrm{Na}$ primeira sessão, ao final de cada tentativa era apresentada uma mensagem de acordo com o desempenho do participante. Respostas com latência menor do que $150 \mathrm{~ms}$ ou emitidas antes da apresentação da pista eram consideradas erros por antecipação e a mensagem "ANTECIPADA" aparecia na tela. Respostas dadas ao estímulo-alvo negativo eram definidas como erros por alarme falso e a mensagem "INCORRETA" aparecia na tela. Respostas com latência superior a $600 \mathrm{~ms}$ eram considerados erros de omissão e a mensagem "LENTA" aparecia na tela. Na segunda sessão, em caso de erro a mensagem "ERR" aparecia na tela. Quando aparecia o estímulo-alvo negativo e nenhuma resposta era dada, ou seja, não houve erro, o número "600" aparecia na tela. Em ambas as sessões, respostas corretas ao estímulo-alvo positivo eram seguidas da apresentação na tela do tempo de reação em 
milisegundos.

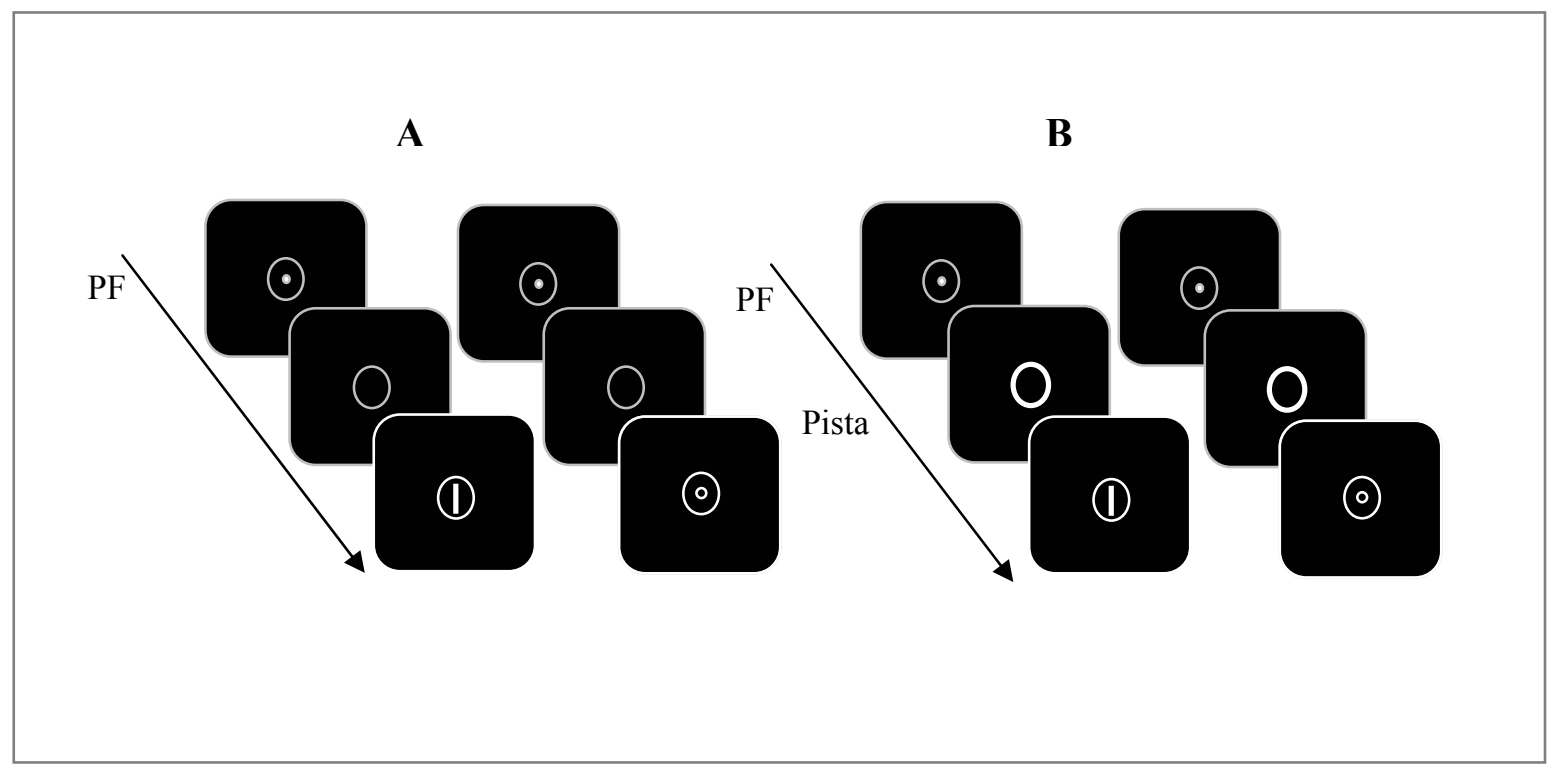

Figura 3.2 - Representação esquemática da seqüência de aparecimento dos estímulos na segunda sessão. Estão representadas as condições sem pista (A) e com pista (B) para o grupo que respondeu à linha. PF: Ponto de Fixação.

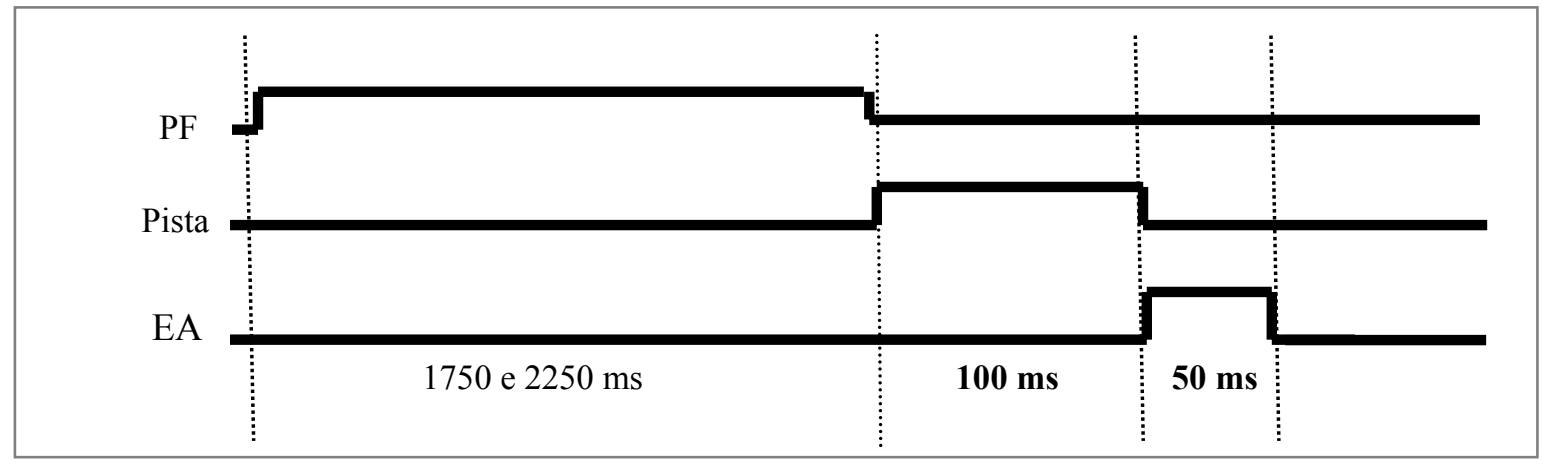

Figura 3.3 - Representação esquemática do padrão temporal da apresentação dos estímulos. EA:estímuloalvo; PF: ponto de fixação. 


\subsubsection{Análise dos dados}

Foram calculadas as medianas dos tempos de reação de cada participante e a média dessas medianas, para cada uma das condições do experimento.

Os dados foram submetidos a uma análise de variância (ANOVA) para medidas repetidas com fatores estímulo-alvo (linha ou cruz) e pista (com pista ou sem pista). Os efeitos que alcançaram probabilidade de erro do tipo I menor ou igual a $0,05(\alpha=0,05)$ foram considerados significativos. No caso de interação entre os fatores, realizou-se a análise post hoc com o teste de Newman-Keuls.

A porcentagem de cada tipo de erro (antecipação, alarme falso e omissão) em relação ao número total de tentativas foi calculada. O número total de tentativas válidas em cada sessão foi 256. Portanto, houve 128 tentativas válidas em que a pista não aparecia e $128 \mathrm{em}$ que era apresentada. O número total de tentativas realizado por cada voluntário em cada condição foi o número de tentativas válidas somado ao número de tentativas em que houve algum tipo de erro. O número de erros de antecipação, alarme falso e omissão nas condições sem pista e com pista foi comparado através do teste de Wilcoxon, sendo aceitos os efeitos que alcançaram probabilidade de erro do tipo I menor ou igual a 0,025.

Os efeitos da pista foram calculados através da subtração entre o tempo de reação para a condição sem pista e o tempo de reação para a condição com pista.

\subsection{Resultados e Discussão}

\subsubsection{Tempo de reação}

Houve efeito principal para o fator pista $(\mathrm{p}<0,01)$, mas não para o fator estímulo-alvo $(p>0,05)$. Não houve interação entre os fatores $(p>0,05)$. Os resultados da ANOVA são mostrados na Tabela 1.

Houve maior tempo de reação na condição com pista em comparação à condição sem

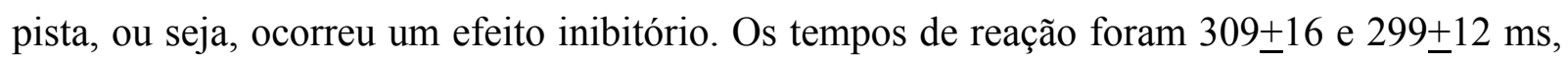
na condição sem pista e 326+9 e 314+10 ms na condição com pista, para linha e cruz, respectivamente (Vide Figura 3.4 e Anexo E). 


\subsubsection{Acurácia}

As porcentagens dos erros de antecipação, alarme falso, omissão para linha e cruz foram, respectivamente, $0,53 \%, 1,34 \%, 0,24 \%$ e $1,24 \%, 1,28 \%$ e $0,14 \%$. O número total de erros de cada tipo para condição está representado na Tabela 2. Não foram obtidas diferenças significativas em relação ao número de erros nas condições sem pista e com pista. Vide ainda tabelas de erros no Anexo E.

Tabela 1 - Resultados da análise de variância tendo como fatores grupo (linha ou cruz) e pista (Com pista e Sem pista). Os resultados significativos estão indicados por $\left(^{*}\right)$.

\begin{tabular}{llll}
\hline Efeito & GL & F & P \\
\hline Estímulo-alvo & 1,14 & 0,441 & 0,517 \\
Pista & 1,14 & $15,278^{*}$ & $0,001^{*}$ \\
Estímulo-alvo x pista & 1,14 & 0,056 & 0,815 \\
\hline
\end{tabular}

GL: graus de liberdade; F: razão entre o quadrado da média do efeito e o do erro; p: nível de significância.

Tabela 2 - Total de erros de antecipação, alarme falso, omissão nas condições sem e com pista, separadamente para linha e cruz.

Linha Cruz

\begin{tabular}{lccc} 
Tipo de erro & Condição & Número de erros & Número de erros \\
\hline \multirow{2}{*}{ Antecipação } & Sem Pista & 4 & 15 \\
& Com Pista & 7 & 11 \\
\multirow{2}{*}{ Alarme falso } & Sem Pista & 12 & 13 \\
& Com Pista & 16 & 14 \\
Omissão & Sem Pista & 3 & 3 \\
& Com Pista & 2 & 0 \\
\hline
\end{tabular}




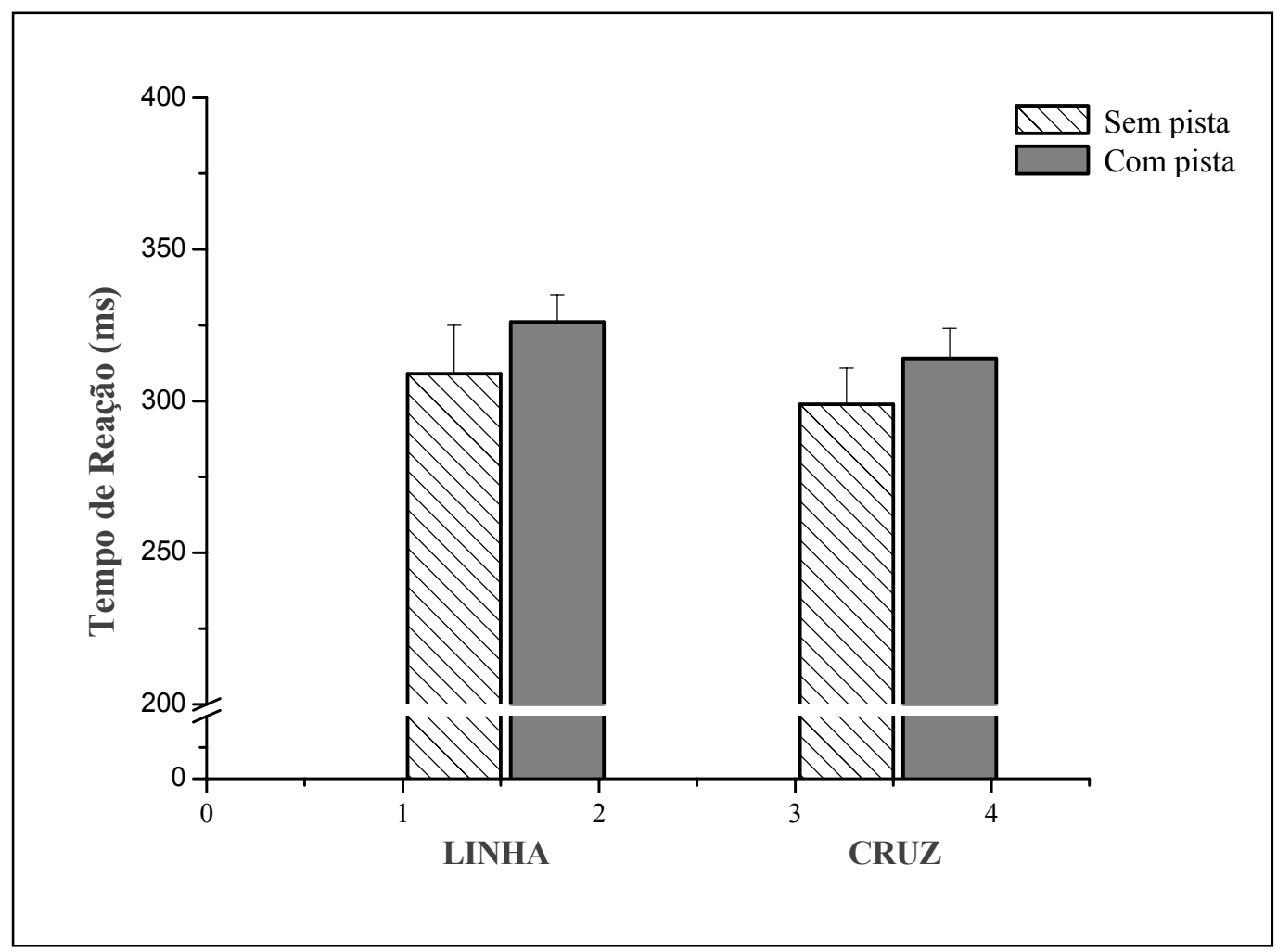

Figura 3.4 - Tempo de reação em milisegundos (média + e.p.m.) para as condições sem pista e com pista, separadamente para linha e cruz.

\subsubsection{Discussão}

Neste experimento, observamos um efeito inibitório da pista no processamento do estímulo-alvo. Acreditamos que o uso de um valor constante de SOA geraria uma expectativa em relação ao momento de aparecimento do estímulo-alvo e, consequentemente, aumentaria o nível de preparação motora. Essa característica da tarefa faria com que a pista iniciasse um processo inibitório que afetaria mecanismos decisionais.

Além disso, uma alternativa seria a ocorrência de um mascaramento anterógrado. A magnitude do mascaramento anterógrado deve atingir seu máximo com uma SOA de $100 \mathrm{~ms}$ (MAYLOR e HOCKEY, 1985), que coincide com o intervalo de tempo utilizado em nosso experimento. Sendo assim, a pista teria interferido no processamento sensorial do estímuloalvo, o que tornaria mais lenta a resposta a ele. 


\section{EXPERIMENTO 2}

O objetivo desse experimento foi verificar se o efeito inibitório da pista observado no Experimento 1 também ocorreria com a apresentação dos estímulos na periferia.

Além disso, investigamos se os efeitos da orientação da atenção para linha e cruz diferem em nossa condição experimental.

\subsection{Material e Métodos}

\subsubsection{Participantes}

Participaram desse experimento 16 voluntários, de ambos os sexos, estudantes de graduação ou pós-graduação da Universidade de São Paulo, selecionados com base nos critérios de inclusão mencionados no Experimento 1.

\subsubsection{Materiais}

O mesmo material descrito no Experimento 1 foi utilizado.

\subsubsection{Procedimento}

O procedimento foi semelhante ao do Experimento 1. Neste experimento, em vez de um anel no centro da tela, foram apresentados quatro anéis, um em cada quadrante. O centro de cada anel estava a $8^{\circ}$ do PF. Todos os estímulos apareceram com a mesma probabilidade em todos os quadrantes. A pista foi apresentada em todas as tentativas. A pista e estímulosalvo foram apresentados metade das vezes na mesma posição e metade das vezes em posições diferentes. As relações espaciais e temporais entre os estímulos estão representados na figuras 4.1 e 4.2 . 


\subsubsection{Análise dos dados}

A análise foi realizada de forma semelhante ao Experimento 1. Os fatores da ANOVA foram posição da pista (mesma ou diferente) e estímulo-alvo (linha ou cruz).

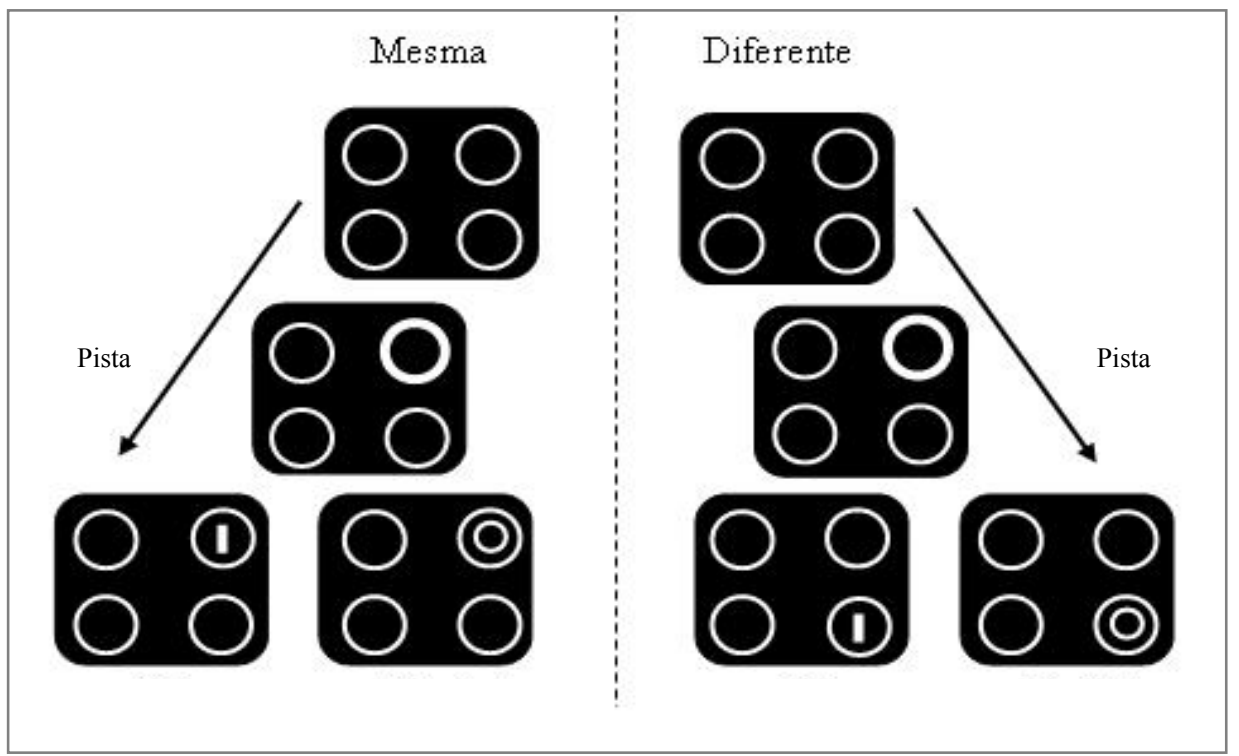

Figura 4.1 - Representação esquemática da relação espacial entre os estímulos. Estão representadas as condições em que pista e estímulo-alvo ocorrem em uma mesma posição (condição Mesma) e em que ocorrem em posições diferentes (condição Diferente), para o grupo que respondeu à linha.

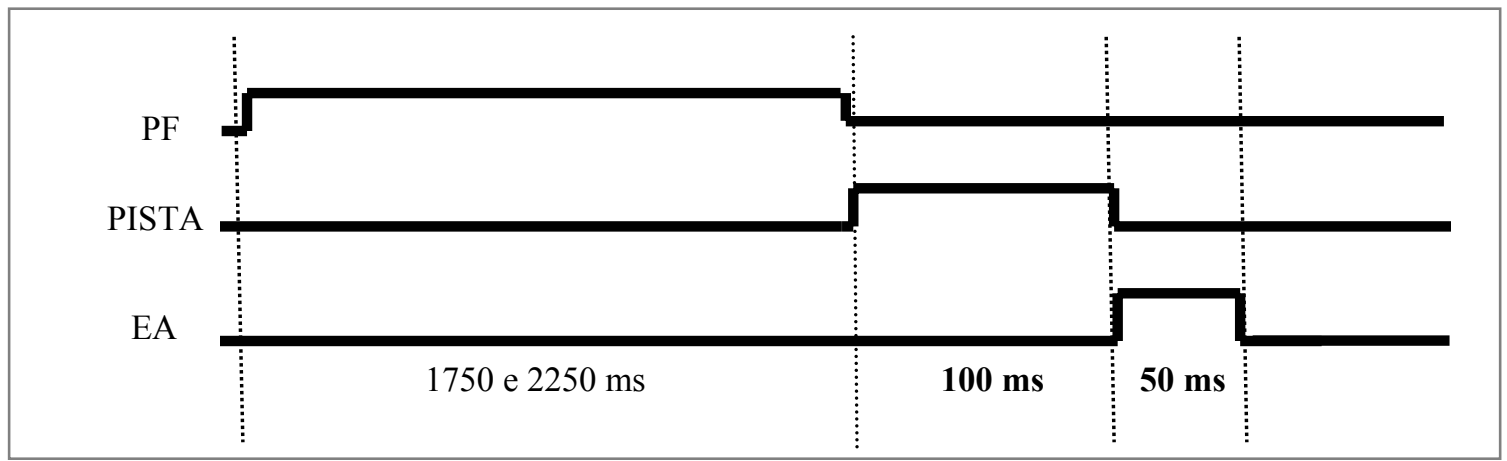

Figura 4.2 - Representação esquemática do padrão temporal da apresentação dos estímulos. EA: estímuloalvo; PF: ponto de fixação. 


\subsection{Resultados e Discussão}

\subsubsection{Tempo de reação}

Houve efeito principal para o fator pista $(\mathrm{p}<0,01)$, mas não para o fator estímulo-alvo ( $p>0.05)$. Não houve interação entre os fatores $(p>0,05)$. Os resultados da análise de variância são apresentados na Tabela 1.

Os tempos de reação foram menores quando pista e estímulo-alvo apareceram na mesma posição, ou seja, houve uma facilitação. Os tempos de reação foram $374 \pm 11$ e $346 \pm 7$

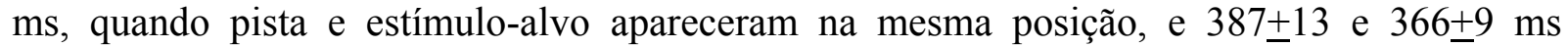
quando apareceram em posições diferentes, para linha e cruz, respectivamente. Vide figura 4.3 e Anexo E.

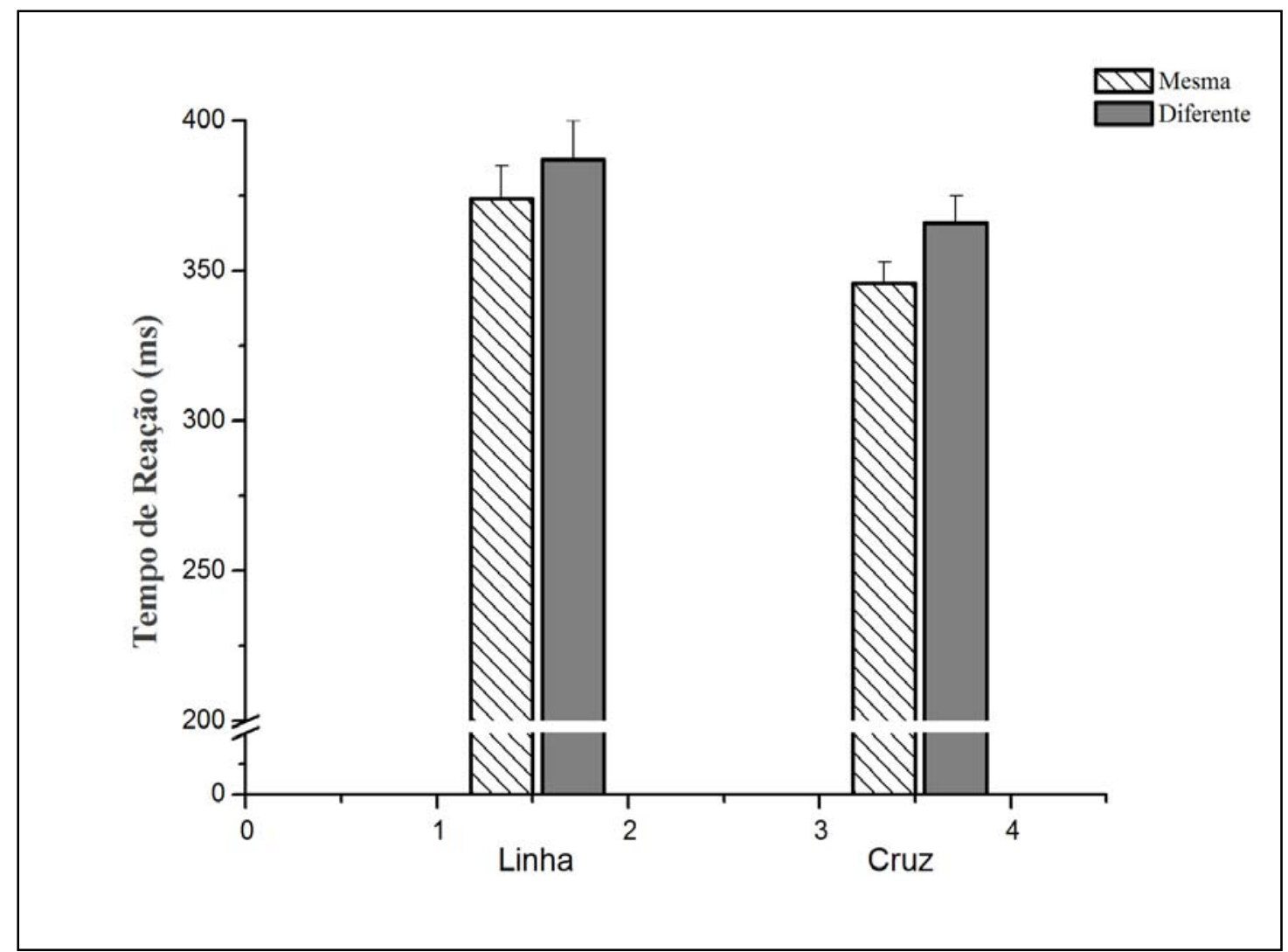

Figura 4.3 - Tempo de reação em milisegundos (média + e.p.m.) para as condições em que pista e estímulo-alvo apareceram na mesma posição e para a condição em que apareceram em posições diferentes, separadamente para os grupos que responderam à cruz e à linha. 
Tabela 3: Resultados da análise de variância tendo como fatores estímulo-alvo (linha ou cruz) e pista (Mesma ou Diferente). Os resultados significativos estão indicados por $\left(^{*}\right)$.

\begin{tabular}{llll}
\hline Efeito & GL & $\mathrm{F}$ & $\mathrm{p}$ \\
\hline Estímulo-alvo & 1,14 & 2,512 & 0,135 \\
Pista & 1,14 & $39,854^{*}$ & $<0,01^{*}$ \\
Estímulo-alvo x Pista & 1,14 & 0,423 & 0,525 \\
\hline
\end{tabular}

GL: graus de liberdade; F: razão entre o quadrado da média do efeito e o do erro; p: nível de significância.

\subsubsection{Acurácia}

As porcentagens dos erros de antecipação, alarme falso, omissão para linha e cruz foram, respectivamente, $0,57 \%, 0,61 \%, 2,17 \%$ e $0,52 \%, 1,61 \%$ e $0,95 \%$. O número total de erros de cada tipo para condição está representado na Tabela 2 e no Anexo E. Não foram obtidas diferenças significativas em relação ao número de erros nas sem pista e com pista.

Tabela 4 - Total de erros por antecipação, alarme falso, omissão nas condições Mesma e Diferente.

\begin{tabular}{llcc}
\hline & & Linha & Cruz \\
\hline Tipo de erro & Condição & Número de erros & Número de erros \\
\hline \multirow{2}{*}{ Antecipação } & Mesma & 7 & 1 \\
& Diferente & 5 & 3 \\
Alarme falso & Mesma & 6 & 13 \\
& Diferente & 4 & 12 \\
Omissão & Mesma & 14 & 3 \\
\hline
\end{tabular}




\subsubsection{Discussão}

Neste experimento, a pista provocou a facilitação do processamento do estímuloalvo, o que seria devido à orientação exógena da atenção espacial para a posição da pista. Além disso, a pista aparecia sempre $100 \mathrm{~ms}$ antes do estímulo-alvo, o que geraria uma orientação da atenção no tempo e também contribuiria para a facilitação observada no experimento.

A orientação da atenção no espaço e no tempo tornam mais rápido o processamento do estímulo-alvo, diminuindo os tempos de reação. Entretanto, a ocorrência simultânea de um processo inibitório poderia afetar os efeitos comportamentais da captura atencional.

A magnitude do mascaramento anterógrado é maior na periferia do campo visual (BRETMEYER, 1984). Se no Experimento 1 houve um mascaramento, ele deve ter se manifestado também neste experimento. Entretanto, a pista diminuiu o tempo de reação, ao invés de aumentá-lo. Consideramos prováveis duas alternativas para explicar os resultados deste experimento: O mascaramento ocorreu, mas não foi suficiente para antagonizar os efeitos atencionais ou não foi a causa dos resultados encontrados no Experimento 1.

Além disso, foi utilizado nesta tarefa um valor constante de SOA, assim como no Experimento 1. Sendo assim, o aumento da preparação motora induzida pela expectativa temporal deve ter ocorrido também neste experimento. Entretanto, como no caso do mascaramento, o efeito inibitório da pista poderia ter sido antagonizado pela facilitação provocada pela pista. Poderíamos ainda pensar que seria importante para o aparecimento do efeito inibitório da pista não só o intervalo de tempo constante entre os estímulos, mas também a sua apresentação sempre no mesmo local. 


\section{EXPERIMENTO 3}

No Experimento 1, observamos um efeito inibitório da pista em uma tarefa vai/nãovai com estímulos centrais e um SOA de $100 \mathrm{~ms}$. Neste experimento, investigamos a manifestação desse efeito da pista ao longo do tempo. Os estímulos foram novamente apresentados no centro da tela e seis valores de SOA (de 100 a $267 \mathrm{~ms}$ ) foram utilizados.

A magnitude do mascaramento anterógrado deve atingir seu máximo com uma SOA de $100 \mathrm{~ms}$ (MAYLOR e HOCKEY, 1985) e tende a diminuir com o tempo (BRETMEYER, 1984). Se o efeito inibitório observado no Experimento 1 fosse causado por um mascaramento, apareceria novamente no SOA de $100 \mathrm{~ms}$ e decairia com o aumento do intervalo de tempo entre os estímulos. Ao contrário, se esse efeito inibitório da pista não fosse encontrado neste experimento, teríamos uma evidência de que o uso de um intervalo de tempo constante entre os estímulos é importante para sua ocorrência.

\subsection{Material e Métodos}

\subsubsection{Participantes}

Participaram desse experimento 16 voluntários, de ambos os sexos, estudantes de graduação ou pós-graduação da Universidade de São Paulo, selecionados com base nos critérios de inclusão mencionados no Experimento1.

\subsubsection{Material}

O mesmo material descrito no Experimento 1 foi utilizado.

\subsubsection{Procedimento}

O procedimento foi bastante semelhante ao do primeiro experimento. Os estímulos, a relação espacial entre eles, assim como as respostas exigidas foram mantidos. Foram utilizados seis valores de SOA (100, 134, 167, 200, 234 e $267 \mathrm{~ms})$, randomizados dentro de cada bloco de testes. A duração da pista continuou $100 \mathrm{~ms}$. Os diferentes valores de SOA foram obtidos variando-se o intervalo entre o fim da pista e o início do estímulo-alvo. As

relações espaciais e temporais entre os estímulos estão representadas nas figuras 4.1 e 4.2. Novamente, os participantes foram divididos em dois grupos conforme o estímulo-alvo ao qual respondiam. 


\subsubsection{Análise de dados}

A análise foi semelhante a do Experimento1. A ANOVA teve como fatores estímuloalvo (linha ou cruz), pista (sem pista ou com pista) e SOA (100, 134, 167, 200, 234, 267 ms).

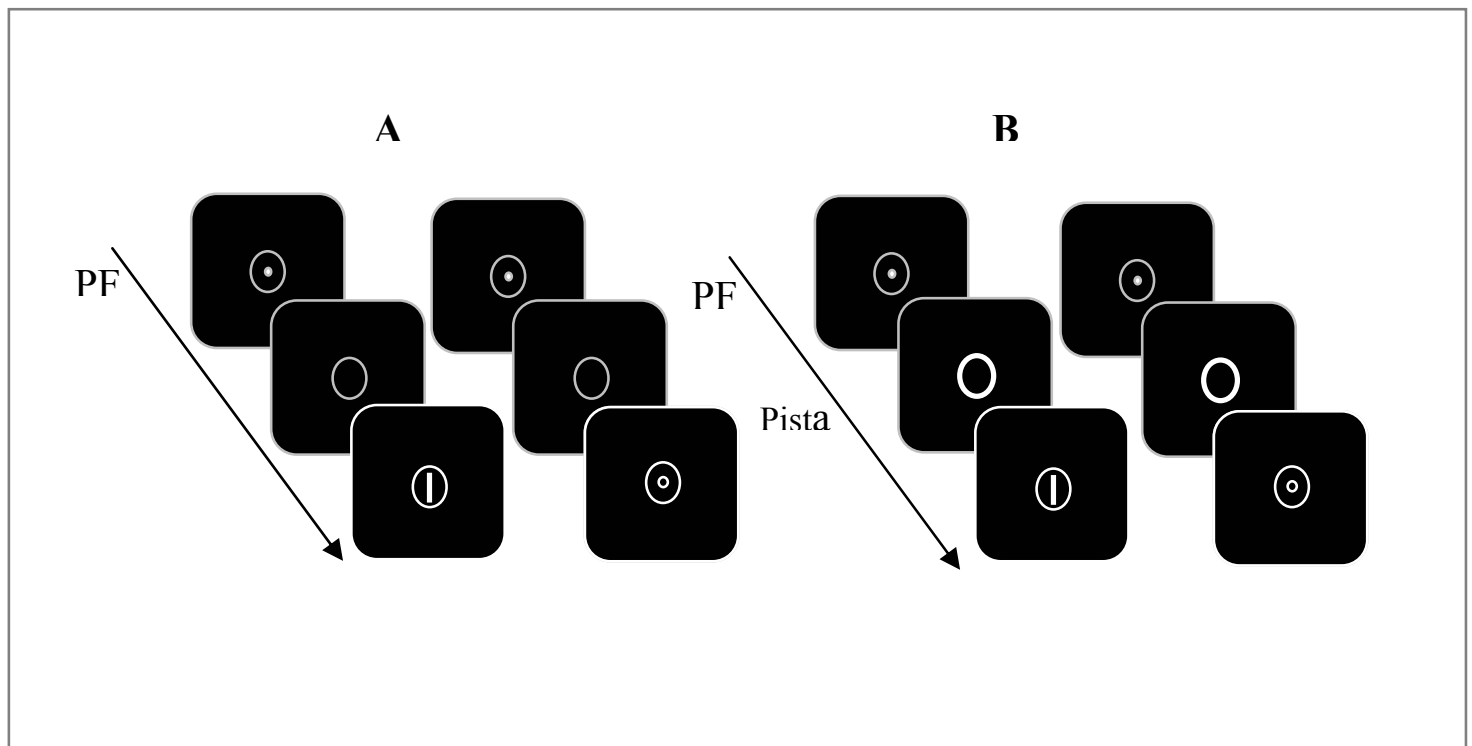

Figura 5.1- Representação esquemática da seqüência de aparecimento dos estímulos. Estão representadas as condições sem pista (A) e com pista (B) para o grupo que respondeu à linha. PF: Ponto de Fixação.

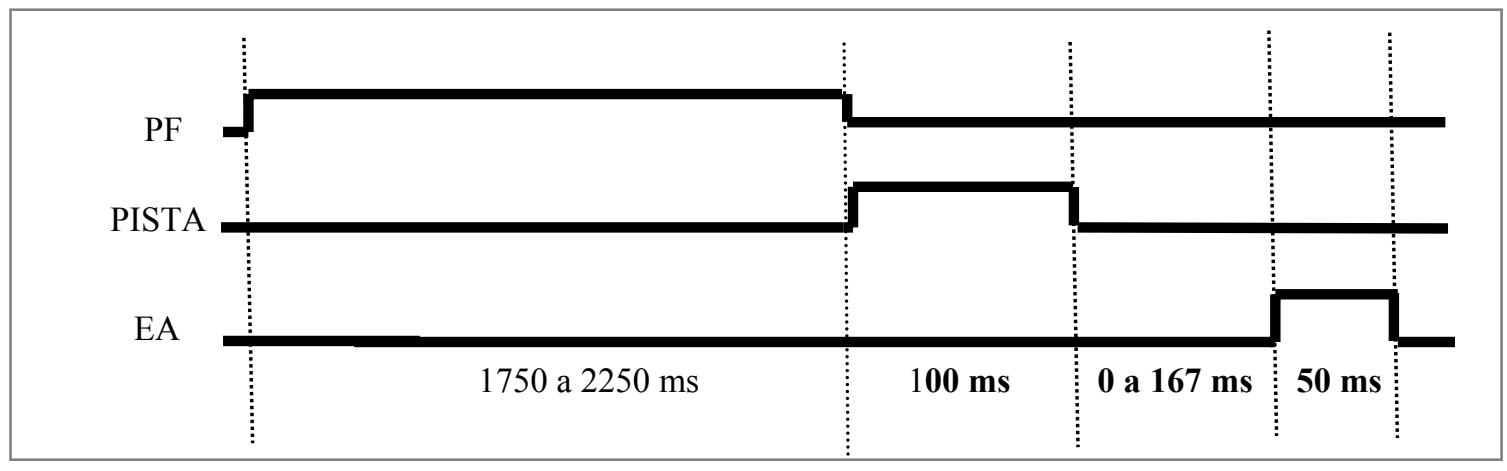

Figura 5.2 - Representação esquemática do padrão temporal de apresentação dos estímulos. EA:estímuloalvo; PF: ponto de fixação. 


\subsection{Resultados e Discussão}

\subsubsection{Tempo de reação}

Não houve efeito principal para os fatores estímulo-alvo e SOA ( $p>0,05)$. Houve efeito principal para o fator pista $(p<0,01)$. Não houve interações significativas entre os fatores. Ocorreu uma interação marginalmente significativa entre os três fatores. $\mathrm{O}$ resultado da ANOVA está apresentado na Tabela 5. As médias dos tempos de reação em cada SOA são apresentadas nas figuras 5.3 e 5.4, assim como na Tabela 23 e na Tabela 25 (Anexo E).

Tabela 5: Resultados da análise de variância tendo como fatores estímulo-alvo (linha ou cruz), pista e SOA. Os resultados significativos estão indicados por $(*)$.

\begin{tabular}{llll}
\hline Efeito & GL & $\mathrm{F}$ & $\mathrm{p}$ \\
\hline Estímulo-alvo & 1,14 & 0,161 & 0,693 \\
Pista & 5,70 & $2,760^{*}$ & $0,024^{*}$ \\
SOA & 1,14 & 2,538 & 0,133 \\
Estímulo-alvo x Pista & 5,70 & 1,396 & 0,236 \\
Estímulo-alvo x SOA & 1,14 & 0,322 & 0,579 \\
Pista x SOA & 5,70 & 0,893 & 0,490 \\
Grupo x Pista x SOA & 5,70 & 2,244 & 0,056 \\
\hline
\end{tabular}

Tabela 6 - Tempos de reação (ms) \pm EPM para linha e cruz, separados por SOA e nas condições sem pista e com pista.

\begin{tabular}{ccccc}
\hline \multirow{2}{*}{ SOA $(\mathrm{ms})$} & Sem Pista & Com Pista & Sem Pista & Com Pista \\
\hline 100 & $304 \pm 12$ & $297 \pm 8$ & $297 \pm 11$ & $299 \pm 11$ \\
134 & $297 \pm 16$ & $298 \pm 11$ & $295 \pm 13$ & $298 \pm 15$ \\
167 & $299 \pm 12$ & $304 \pm 11$ & $287 \pm 11$ & $297 \pm 12$ \\
200 & $297 \pm 14$ & $308 \pm 13$ & $282 \pm 13$ & $290+12$ \\
234 & $290 \pm 11$ & $295 \pm 9$ & $280 \pm 12$ & $283 \pm 10$ \\
267 & $277 \pm 12$ & $294 \pm 16$ & $294 \pm 15$ & $283 \pm 12$
\end{tabular}




\subsection{2 - Acurácia}

Não houve diferença significativa entre o número nas condições sem e com pista. As porcentagens dos erros por alarme falso, omissão e antecipação para a linha e para a cruz são, respectivamente, $2,01 \%, 1,92 \%, 0,19 \%$ e $0,91 \%, 1,05 \%$ e $0,29 \%$. O número total de cada tipo de erro, separados por SOA estão representados nas figuras 5.3 e 5.4, na Tabela 6 e no Anexo E.

Tabela 7: Total de erros por antecipação, alarme falso e omissão nas condições Sem pista e Com pista, para a linha e para a cruz.

\begin{tabular}{ccccccc}
\hline & Alarme falso & \multicolumn{2}{c}{ Antecipação } & \multicolumn{2}{c}{ Omissão } \\
\hline $\begin{array}{c}\text { Estímulo- } \\
\text { alvo }\end{array}$ & Sem Pista & Com Pista & Sem Pista & Com Pista & Sem Pista & Com Pista \\
\hline Linha & 21 & 22 & 18 & 23 & 4 & 0 \\
Cruz & 10 & 9 & 4 & 18 & 2 & 4 \\
\hline
\end{tabular}

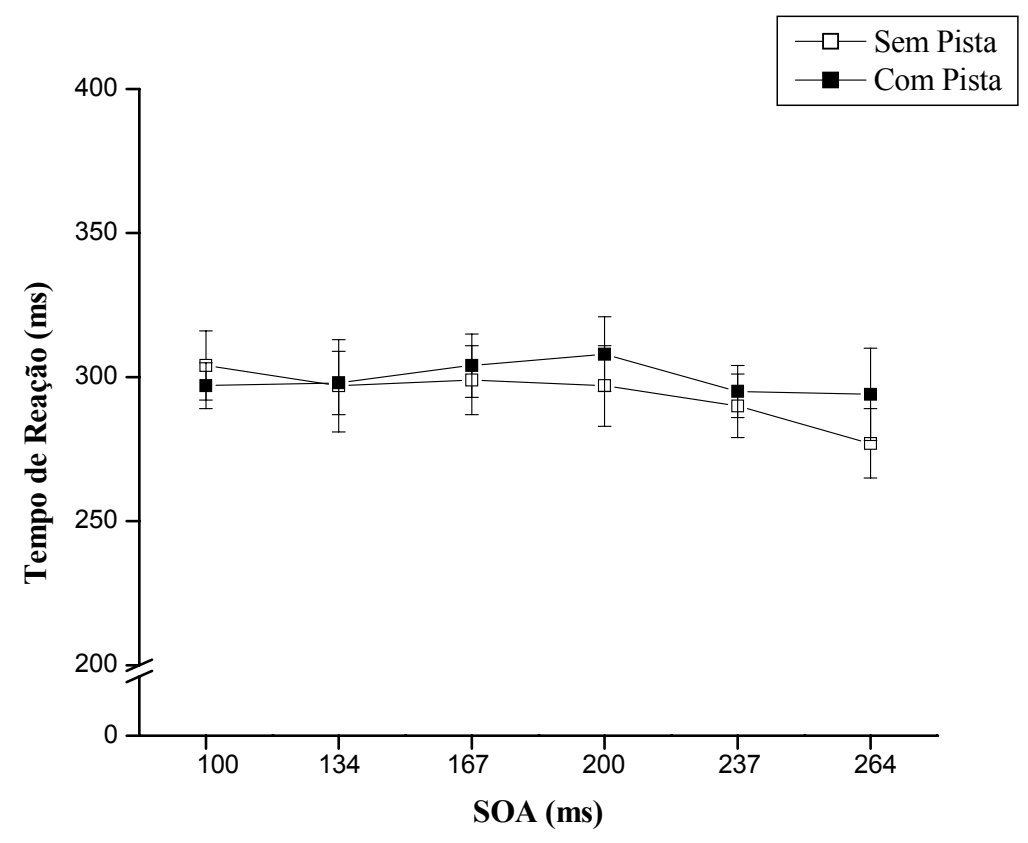

Figura 5.3 - Tempo de reação para a linha (média + e.p.m). Estão representadas as condições sem pista e com pista, para cada SOA. 


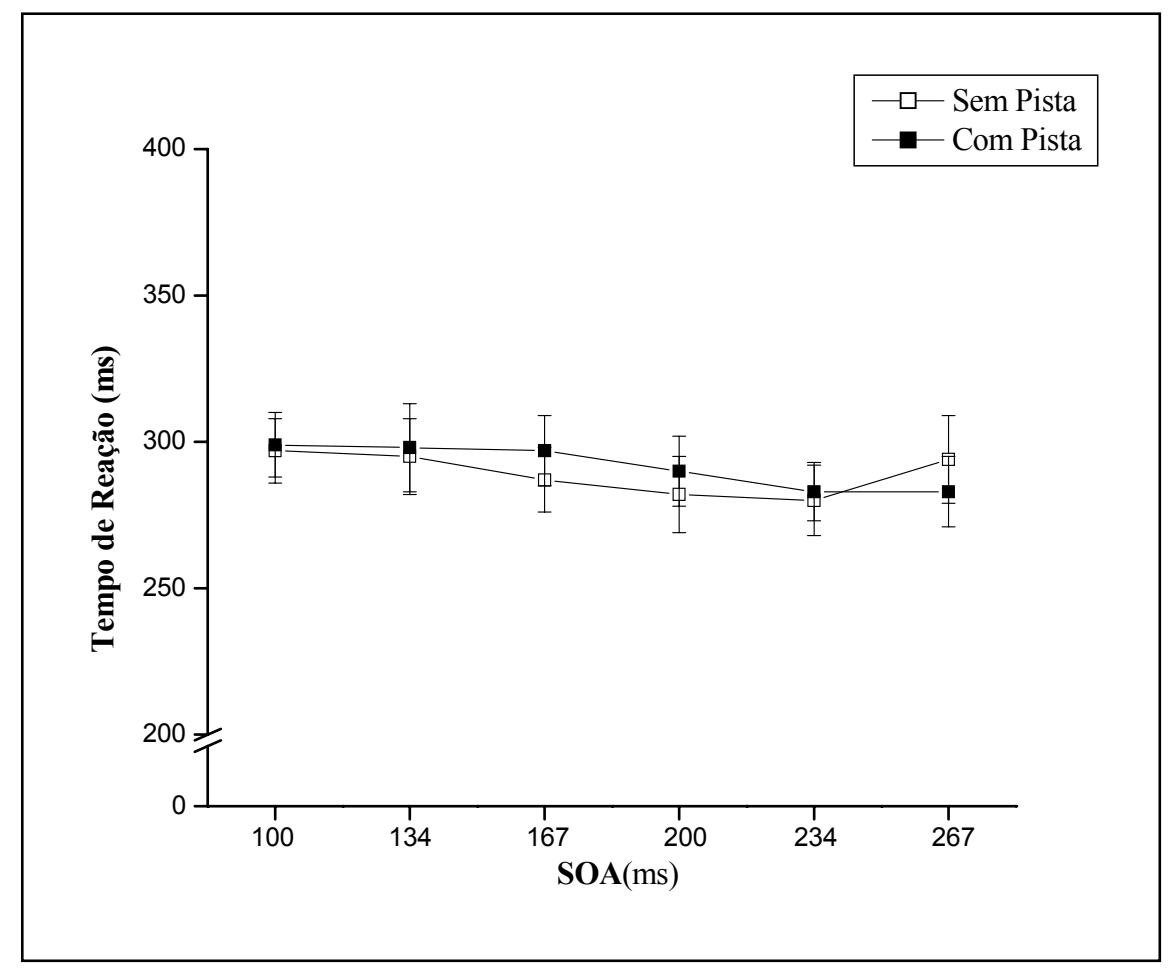

Figura 5.4 - Tempo de reação para a cruz (média + e.p.m). Estão representadas as condições sem pista e com pista, para cada SOA.

\subsection{3 - Discussão}

Não encontramos o efeito inibitório da pista no SOA de $100 \mathrm{~ms}$, como no Experimento 1. Se esse efeito aparecesse novamente no SOA de $100 \mathrm{~ms}$ e sua magnitude decaísse com o tempo, teríamos uma forte evidência de que foi causado por um mascaramento anterógrado. Os resultados deste experimento sugerem que a manifestação do efeito inibitório da pista observado no Experimento 1 depende do uso de um intervalo de tempo constante entre pista e estímulo-alvo.

A manifestação do mascaramento depende das características físicas dos estímulos e ocorre quando há proximidade no tempo e no espaço entre eles (BREITMEYER, 1984). Os estímulos utilizados neste experimento foram os mesmos do Experimento 1, assim como a relação espacial entre eles. O mascaramento não deveria desaparecer apenas porque o SOA deixa de ter um único valor e passa a ter valores variáveis. Ao contrário, estudos sobre mascaramento tipicamente usam diversos valores de SOA e analisam a magnitude desse fenômeno em função do tempo.

Existem alguns problemas metodológicos no experimento 3. O poder da análise 
estatística pode ter diminuído pelo uso de seis valores de SOA. Entretanto, uma metodologia semelhante foi usada em nosso laboratório por Otta e Ribeiro-do-Valle (2001) para investigar a evolução temporal do mascaramento anterógrado. Esses autores realizaram um experimento com estímulos centrais e seis valores de SOA (zero, 17, 34, 67, 84 e $100 \mathrm{~ms}$ ). O efeito observado foi um aumento gradual da magnitude do mascaramento, que atingiu seu máximo no SOA de $100 \mathrm{~ms}$. Se foi possível mostrar o aumento da magnitude do mascaramento com o aumento do valor de SOA no trabalho de Otta e Ribeiro-do-Valle (2001), esperávamos também evidenciar a diminuição da intensidade desse fenômeno ao longo do tempo no Experimento 3.

Quando o intervalo entre o início dos estímulos é variado ao longo do teste, como neste experimento 3, a facilitação provocada pela orientação da atenção no tempo é tipicamente maior no intervalo de tempo mais longo (CORREA et al., 2006). Esse resultado pode ser visto no SOA de 267 ms quando o estímulo-alvo foi a cruz, mas não quando foi a linha. No caso desse último estímulo, houve um efeito inibitório da pista no SOA mais longo.Esse resultado poderia se dever a um aumento no critério de resposta na condição com pista em comparação à condição sem pista, como propuseram Ivanoff e Klein (2001). Não observamos diferenças significativas em relação ao número de erros sem pista e com pista. Entretanto, nosso desenho experimental visa à avaliação do tempo de reação e não seria o mais adequado para avaliação da acurácia. 


\section{EXPERIMENTO 4}

Os resultados do Experimento 3 sugerem que a manifestação do efeito inibitório da pista observado no Experimento1 depende da expectativa temporal gerada pelo uso de um único valor de SOA. Por isso, neste experimento usamos um SOA de $200 \mathrm{~ms}$ em todas as tentativas. Se um resultado similar àquele do Experimento 1 fosse encontrado, confirmaríamos a importância de um intervalo fixo entre os estímulos para o aparecimento do efeito inibitório da pista.

No entanto, a diferença entre o Experimento 1 e o Experimento 3 não reside apenas no uso de um ou mais valores de SOA. No Experimento 1, o intervalo entre o fim da pista e o início do estímulo-alvo é zero, enquanto no Experimento 3 ele é variado. Esse intervalo de tempo entre o desaparecimento da pista e o surgimento do estímulo-alvo poderia ter importância para a observação do efeito inibitório da pista. Por isso, os participantes foram divididos em dois grupos, conforme a duração do intervalo entre os estímulos.

Como não obtivemos diferenças entre linha e cruz nos experimentos anteriores que justificassem a utilização desses dois estímulos, optamos por utilizar apenas a linha como estímulo-alvo.

\subsection{Material e Métodos}

\subsubsection{Participantes}

Participaram desse experimento 16 voluntários, de ambos os sexos, estudantes de graduação ou pós-graduação da Universidade de São Paulo, selecionados com base nos critérios de inclusão mencionados no Experimento 1.

\subsubsection{Material}

O mesmo material descrito no Experimento 1 foi utilizado.

\subsubsection{Procedimento}

O procedimento foi semelhante ao do Experimento 1. O valor de SOA foi sempre 200 ms. Os voluntários foram divididos em grupo 1 e grupo 2. No grupo 1, a pista durou $100 \mathrm{~ms}$ e o intervalo entre o fim da pista e o início do estímulo-alvo foi de $100 \mathrm{~ms}$. No grupo 2, a pista durou $200 \mathrm{~ms}$ e o intervalo entre os estímulos foi zero. As relações espaciais e temporais entre 
os estímulos foram as mesmas do Experimento 1 e estão representadas nas figuras 6.1, 6.2 e 6.3 .

\subsubsection{Análise dos dados}

A análise estatística foi semelhante àquela utilizada no primeiro experimento. Os fatores da ANOVA foram grupo (1 ou 2) e pista (sem pista ou com pista).

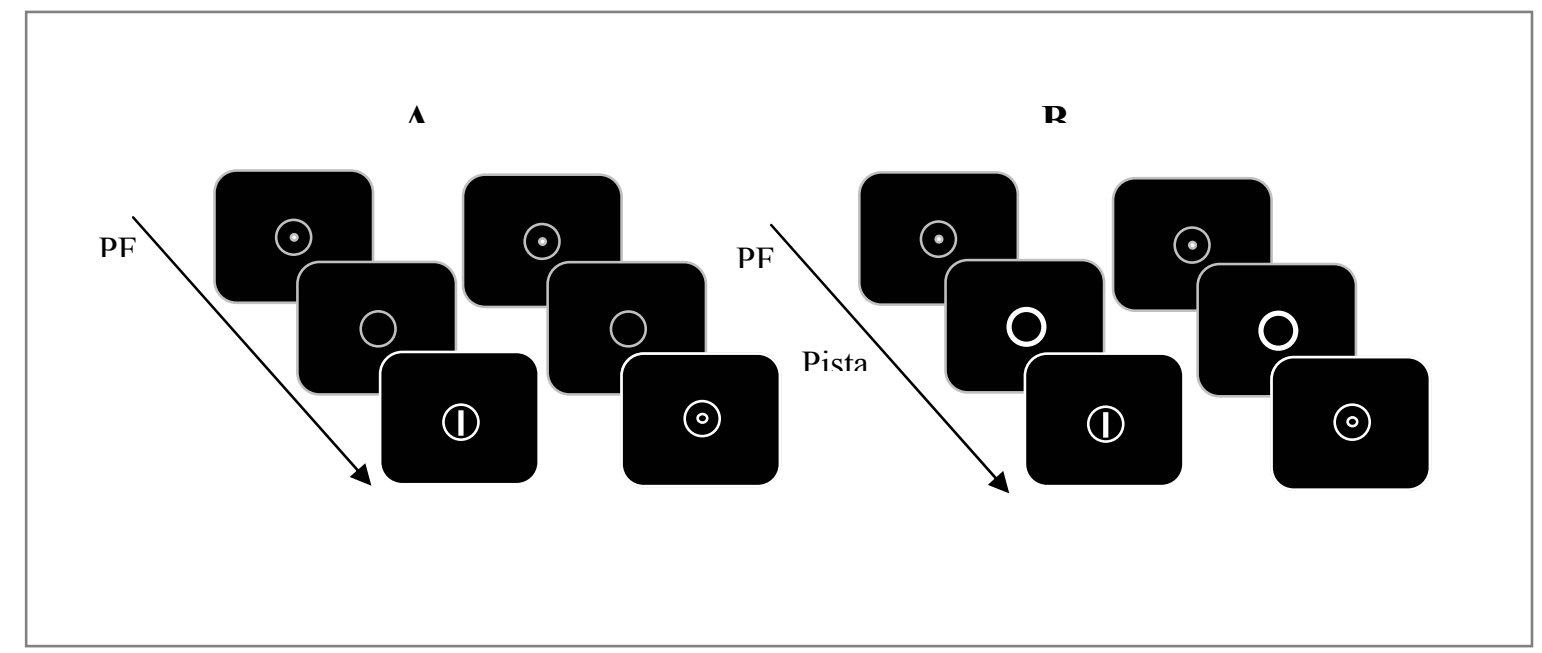

Figura 6.1- Representação esquemática da seqüência de aparecimento dos estímulos na segunda sessão. Estão representadas as condições sem pista (A) e com pista (B) para o grupo que respondeu à linha. PF: Ponto de Fixação.

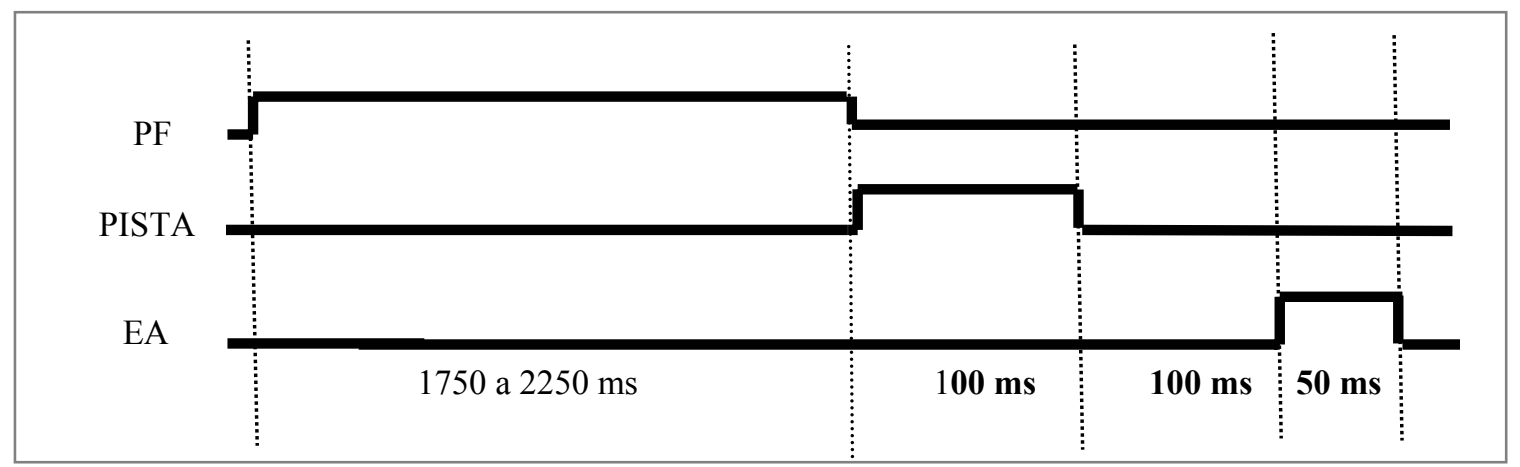

Figura 6.2 - Representação esquemática do padrão temporal da apresentação dos estímulos no Grupo 1. EA:estímulo-alvo; PF: ponto de fixação. 


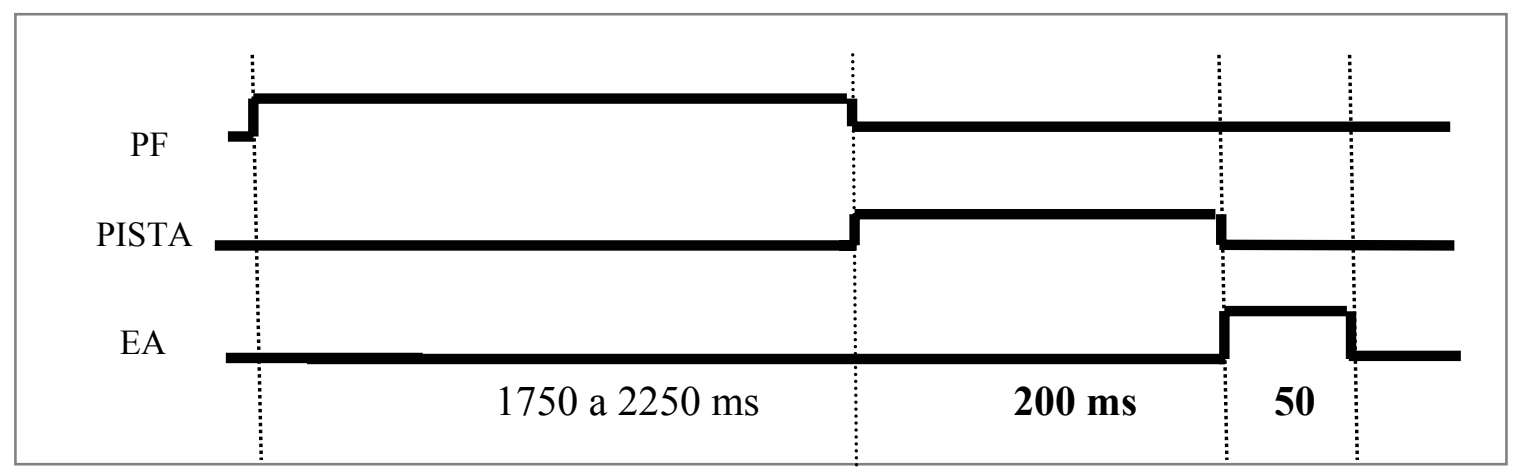

Figura 6.3 - Representação esquemática do padrão temporal da apresentação dos estímulos no Grupo 2 . EA:estímulo-alvo; PF: ponto de fixação.

\subsection{Resultados e Discussão}

\subsubsection{Tempo de reação}

Houve efeito principal para o fator pista $(\mathrm{p}<0,01)$, mas não para o fator estímulo-alvo $(\mathrm{p}>0,05)$. Houve um maior tempo de reação na condição com pista em comparação à condição sem pista. Os tempos de reação para os Grupo 1 e para o Grupo 2 foram, respectivamente, $260 \pm 9 \mathrm{~ms}$ e $250 \pm 10$, sem pista, e $272 \pm 6$ e $278 \pm 10 \mathrm{~ms}$, com pista. Houve interação entre os fatores $(p=0,013)$. A magnitude do efeito inibitório foi maior no Grupo 2 que no Grupo 1. A análise de variância está apresentada na Tabela 8. Os tempos de reação são apresentados na Figura 6.3 e no Anexo E.

Tabela 10: Resultados da análise de variância tendo como fatores grupo (1 ou 2) e pista (Sem Pista e Com Pista). Os resultados significativos estão indicados por (*).

\begin{tabular}{llll}
\hline Efeito & GL & F & P \\
\hline Grupo & 1,14 & 0,033 & 0,857 \\
Estímulo Precedente (Pista) & 1,14 & $52,579^{*}$ & $<0,01^{*}$ \\
Grupo x Pista & 1,14 & $8,049^{*}$ & $0,013^{*}$ \\
\hline
\end{tabular}

GL: graus de liberdade; F: razão entre o quadrado da média do efeito e o do erro; p: nível de significância. 


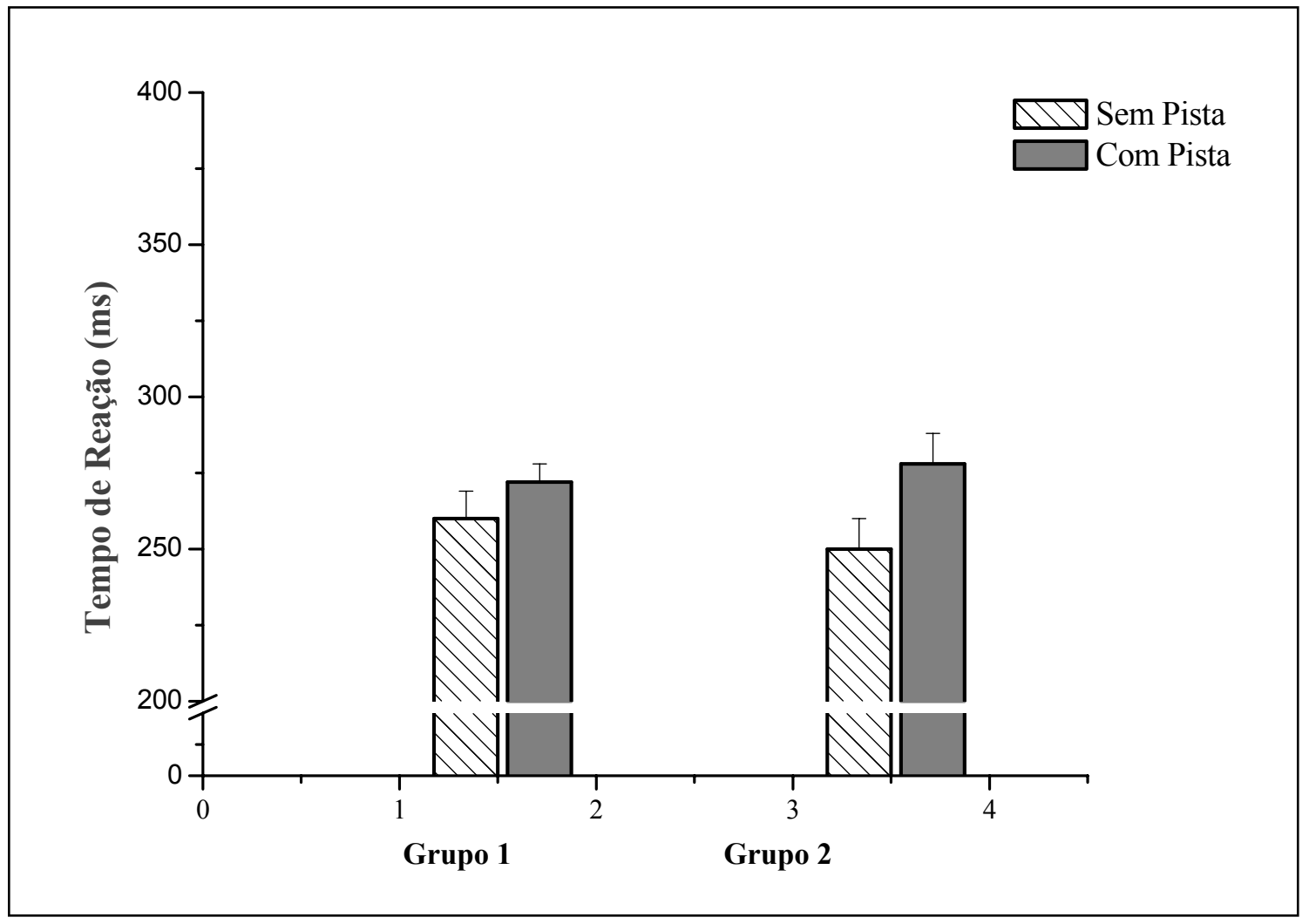

Figura 6.3 - Tempo de reação em milisegundos (média \pm e.p.m.) para as condições sem pista e com pista, separadamente para os grupos 1 e 2 .

\subsubsection{Acurácia}

Não foi obtida qualquer diferença significativa em relação aos erros nas condições sem pista e com pista. As porcentagens dos erros de antecipação, alarme falso e omissão para os grupos 1 e 2 são, respectivamente 1,$42 ; 1,66$ e $0,05 \%$ e 1,24; 0,62 e 0,24\%. O número total de erros de cada tipo está na Tabela 9. 
Tabela 9: Total de erros de antecipação, alarme falso e omissão nas condições sem pista e com pista, separadamente para os grupos 1 e 2.

\begin{tabular}{lccc}
\hline & & Grupo 1 & Grupo 2 \\
\hline \multirow{2}{*}{ Antecipação } & Sem Pista & 9 & 12 \\
& Com Pista & 17 & 18 \\
\multirow{2}{*}{ Alarme falso } & Sem Pista & 6 & 23 \\
\multirow{2}{*}{ Omissão } & Com Pista & 7 & 12 \\
& Sem Pista & 1 & 0 \\
\hline
\end{tabular}

\subsubsection{Discussão}

Neste experimento, observamos o efeito inibitório da pista para ambos os grupos. Isto significa que a manifestação da inibição observada no Experimento 1 depende realmente de um intervalo de tempo fixo entre pista e estímulo-alvo.

O uso de um único valor de SOA gera uma forte expectativa temporal. Conhecer o momento em que uma informação relevante aparecerá permite que a resposta seja preparada em antecipação a ela (CORREA et al., 2004; COULL, 2004). Além disso, na tarefa usada neste experimento, a resposta sempre é direcionada a uma mesma posição do espaço. Essas características conferem a essa tarefa de tempo de reação vai/não-vai um alto nível de preparação motora. Os resultados deste experimento sugerem que o nível de preparação motora é importante para o aparecimento do efeito inibitório da pista.

O efeito inibitório da pista foi maior para o Grupo 2, no qual o intervalo entre o fim da pista e o início do estímulo-alvo foi zero. Esse resultado favoreceria a proposta de que os resultados do Experimento 1 se devem a um mascaramento anterógrado. 


\section{EXPERIMENTO 5}

Os resultados dos experimentos anteriores sugerem que o efeito inibitório da pista observado no Experimento 1 e no Experimento 4 dependem do nível de preparação motora na tarefa. Por isso, neste experimento, utilizamos uma tarefa de escolha, em que o nível de preparação motora é menor que nas tarefas vai/nã-vai. Com isso, esperávamos que o efeito inibitório da pista se tornasse menos intenso ou não fosse mais observado

\subsection{Material e Métodos}

\subsubsection{Participantes}

Participaram desse experimento 8 voluntários, de ambos os sexos, estudantes de graduação ou pós-graduação da Universidade de São Paulo, selecionados com base nos critérios de inclusão mencionados no Experimento 1.

\subsubsection{Material}

O material foi o mesmo descrito no Experimento 1, com apenas uma exceção. Havia duas teclas para resposta, uma posicionada do lado direito e outra do lado esquerdo dos voluntários.

\subsubsection{Procedimento}

O procedimento foi semelhante àquele descrito no Experimento 1. Os estímulos-alvo foram a linha ou o anel. Os voluntários eram instruídos a responder ao estímulo-alvo o mais rápido possível com a mão do lado correspondente a ele. A mão de resposta foi alternada entre os voluntários de modo que metade respondesse à linha com a mão direita e ao anel com a mão esquerda (Grupo LDAE) e metade respondesse à linha com a mão esquerda e ao anel com a mão direita (Grupo LEAD). Quando a mão de resposta era trocada ocorriam os chamados

erros por inversão. A pista era apresentada em $50 \%$ das vezes. As relações espaciais e temporais entre os estímulos estão representadas, respectivamente, nas figuras 6.1 e 6.2.

\subsubsection{Análise dos dados}

A análise estatística foi realizada de forma semelhante ao Experimento 1. Os fatores da ANOVA foram grupo (LDAE e LEAD), estímulo-alvo (linha ou anel) e pista (sem pista e com pista). 


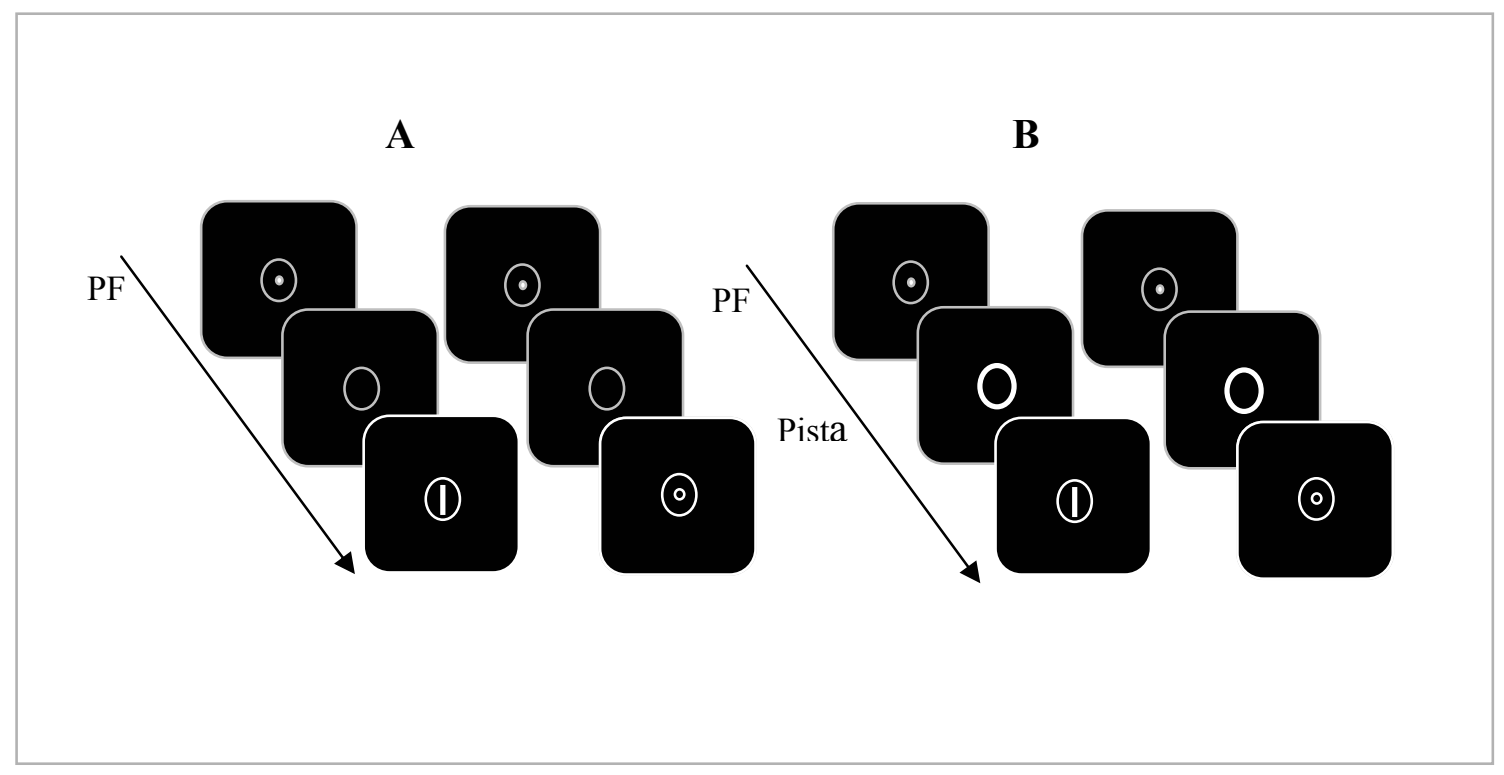

Figura 6.1 - Representação esquemática do padrão espacial da apresentação dos estímulos no Experimento 5, sem pista (A) e com pista (B). PF: ponto de fixação.

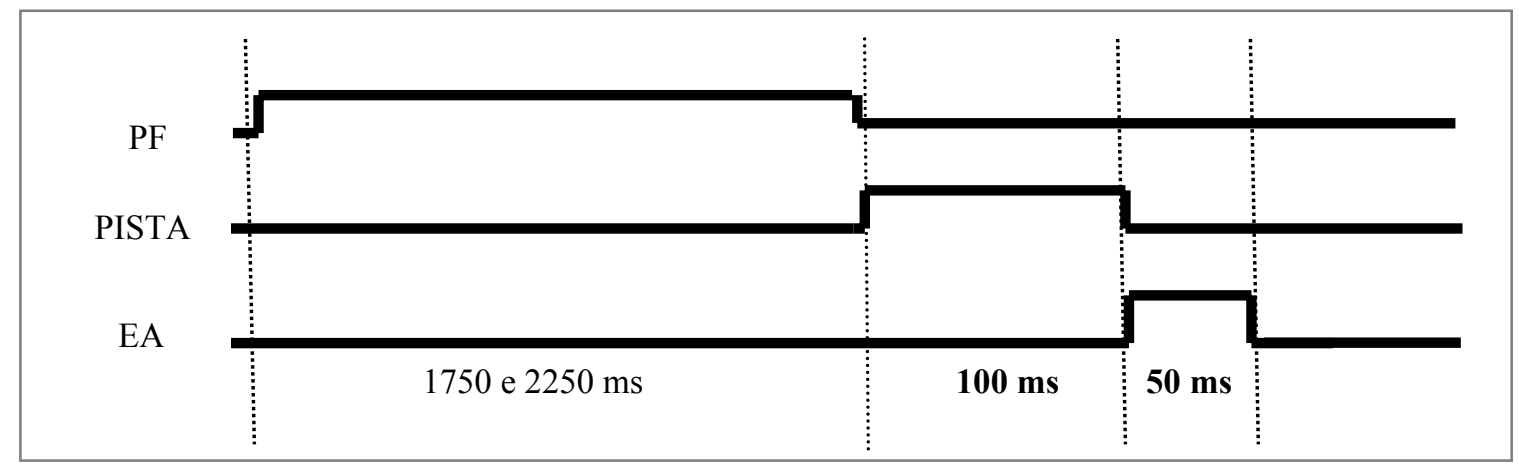

Figura 6.2 - Representação esquemática do padrão temporal da apresentação dos estímulos no Experimento 5. EA:estímulo-alvo; PF: ponto de fixação.

\subsection{Resultados e Discussão}

\subsubsection{Tempo de reação}

Não houve efeito principal para os fatores grupo, estímulo-alvo ou pista $(\mathrm{p}>0,05)$. Não houve interação entre os fatores $(p>0,05)$. A análise de variância está apresentada na Tabela 11. Como não houve diferença entre os grupos ou entre os estímulos-alvo, realizamos um teste $\mathrm{t}$ para amostras dependentes, para comparar os tempos de reação sem pista e com Pista. Novamente não observamos uma diferença significativa entre essas duas condições 
$(\mathrm{p}=0,383)$. Os tempos de reação sem pista e com pista foram, respectivamente, $348 \pm 10$ e 354+9 e estão representados na Figura 6.3. Os tempos de reação para linha e anel nos LDAE e LEAD estão representados separadamente na Tabela 31 (Anexo E).

Tabela 11: Resultados da análise de variância tendo como fatores grupo (1 ou 2) e pista (Ausente ou presente). Os resultados significativos estão indicados por $(*)$.

\begin{tabular}{lccc}
\hline Efeito & GL & F & P \\
\hline Grupo & 1,6 & 0,444 & 0,857 \\
Estímulo-alvo & 1,6 & 0,591 & 0,471 \\
Pista & 1,6 & 1,323 & 0,293 \\
Grupo x Estímulo-alvo & 1,6 & 2,548 & 0,161 \\
Grupo x Pista & 1,6 & 0,115 & 0,745 \\
Estímulo-alvo x pista & 1,6 & 0,531 & 0,493 \\
Grupo x estímulo-alvo x pista & 1,6 & 5,675 & 0,546
\end{tabular}

GL: graus de liberdade; F: razão entre o quadrado da média do efeito e o do erro; p: nível de significância.

\subsubsection{Acurácia}

As porcentagens dos erros de antecipação, alarme falso e omissão são, respectivamente, $1,25 \%, 3,23 \%$ e $0,97 \%$. Não foram obtidas diferenças estatisticamente significativas na comparação entre o número de erros sem e com pista. O número total de erros em cada condição está representado na Tabela 13.

Tabela 13: Total de erros de antecipação, inversão e omissão nas condições sem pista e com pista.

\begin{tabular}{llc}
\hline Tipo de erro & & Número de erros \\
\hline \multirow{2}{*}{ Antecipação } & Sem pista & 15 \\
& Com pista & 12 \\
Inversão & Sem pista & 20 \\
& Com pista & 50 \\
Omissão & Com pista & 13 \\
& Sem pista & 8 \\
\hline
\end{tabular}




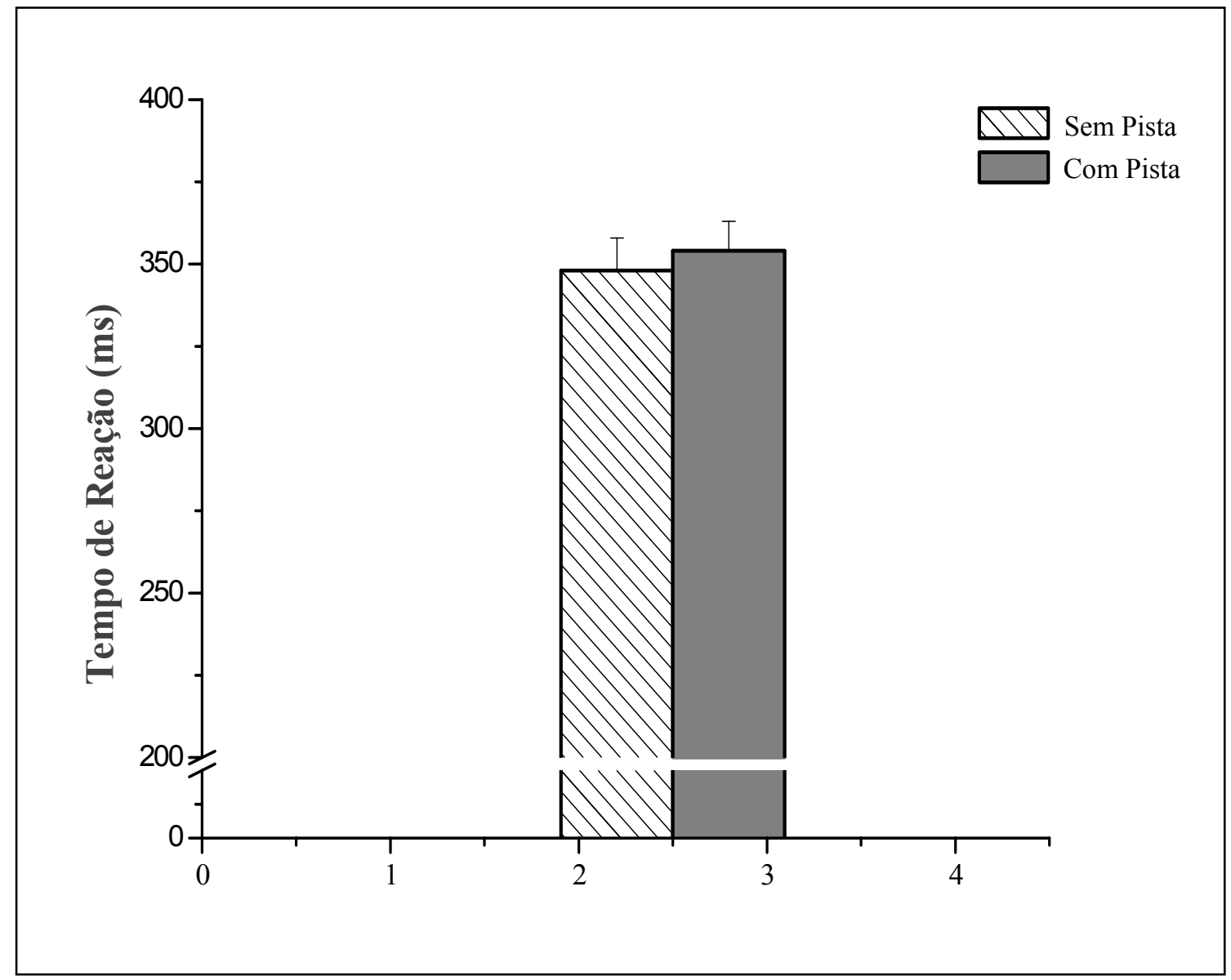

Figura 6.3 - Tempo de reação em milisegundos (média \pm e.p.m.) para as condições sem pista e com pista.

\subsubsection{Discussão}

Não observamos um efeito significativo da pista neste quinto experimento, apesar de os mesmos estímulos e o mesmo SOA do Experimento 1 terem sido utilizados. Se o efeito inibitório da pista observado no Experimento 1 fosse devido a um mascaramento anterógrado, teria ocorrido também na tarefa de escolha.

Os resultados deste Experimento sugerem que o nível de preparação motora é realmente importante para a ocorrência do efeito inibitório observado no Experimento 1 e no Experimento 4. 


\section{EXPERIMENTO 6}

Os resultados do Experimento 5 indicam que o nível de preparação motora é importante para a manifestação do efeito inibitório observado no Experimento 1 e no Experimento 4 deste trabalho. Sendo assim, se o efeito inibitório da pista não foi observado com a diminuição no nível de preparação motora, o contrário deveria ocorrer se o nível de preparação motora aumentasse. Por isso, neste experimento, utilizamos uma tarefa de detecção.

\subsection{Material e Métodos}

\subsubsection{Participantes}

Participaram desse experimento 8 voluntários, ambos os sexos, estudantes de graduação ou pós-graduação da Universidade de São Paulo, selecionados com base nos critérios de inclusão mencionados no Experimento 1.

\subsubsection{Material}

O mesmo material descrito no Experimento 1 foi utilizado.

\subsubsection{Procedimento}

O procedimento foi semelhante àquele do Experimento 1. O estímulo-alvo consistia na linha vertical e aparecia em 50\% das tentativas. Nenhum estímulo-alvo era apresentado nas demais tentativas. Respostas dadas na ausência do estímulo-alvo negativo eram definidas como erro por Alarme falso. As relações espaciais e temporais entre os estímulos estão representadas, respectivamente, nas figuras 8.1 e 8.2 .

\subsubsection{Análise dos dados}

A análise estatística foi semelhante àquela utilizada no primeiro experimento. $\mathrm{O}$ teste $\mathrm{t}$ para amostras dependentes foi utilizado para comparar os tempos de reação sem e com pista. 


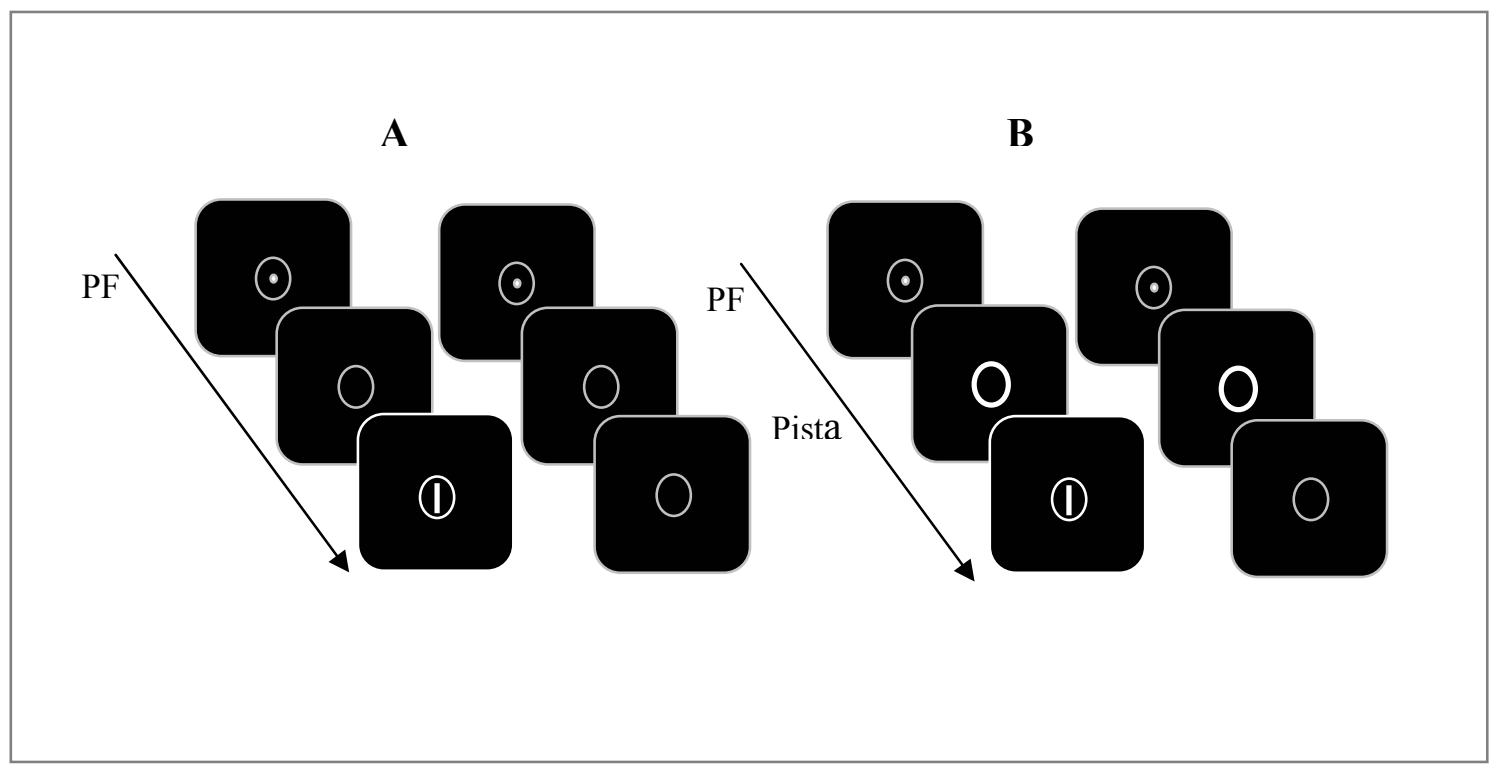

Figura 8.1 - Representação esquemática da seqüência de aparecimento dos estímulos na segunda sessão, incluindo as condições sem pista (A) e com pista (B).

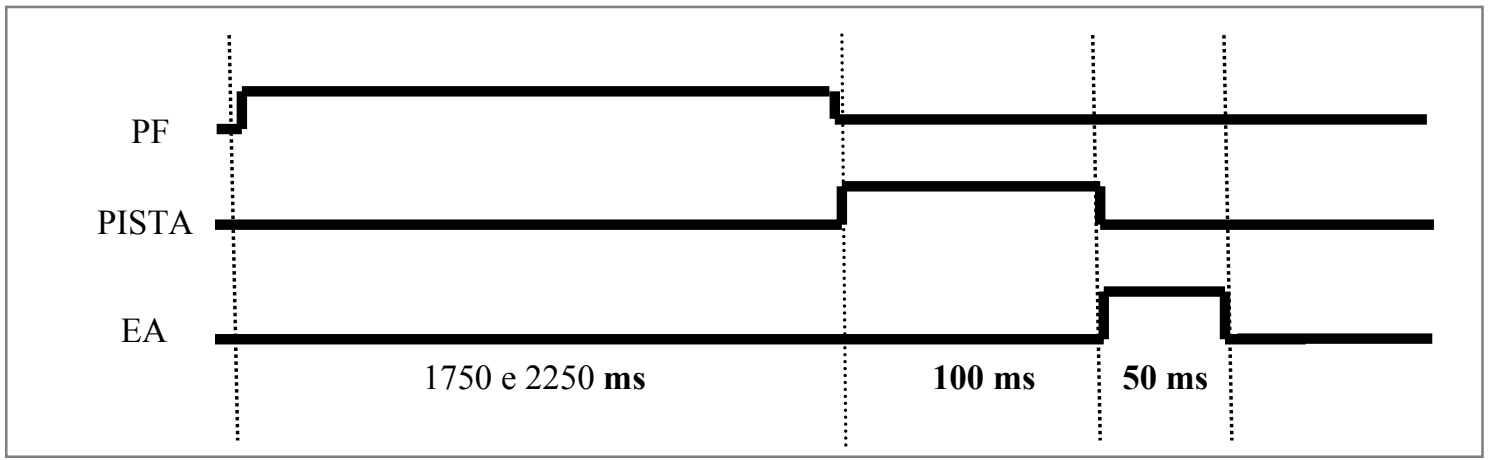

Figura 8.2 - Representação esquemática do padrão temporal da apresentação dos estímulos. EA:estímulo-alvo; PF: ponto de fixação.

\subsection{Resultados e Discussão}

\subsubsection{Tempo de reação}

Os tempos de reação para as condições sem pista e com pista foram, respectivamente, $301 \pm 14$ e $284 \pm 10 \mathrm{~ms}$. O tempo de reação quando foi $17 \mathrm{~ms}$ menor quando a pista era apresentada em comparação a quando ela não era $(p=0,037)$. Os tempos de reação estão representados na figura 8.3 . 


\subsubsection{Acurácia}

Não foi obtida qualquer diferença significativa em relação aos erros na ausência e na presença da pista. As porcentagens dos erros por antecipação, Alarme falso e omissão foram, respectivamente, $1,24 \%, 0,71 \%, 0,76 \%$. O número total de erros de cada tipo está indicado na Tabela 10.

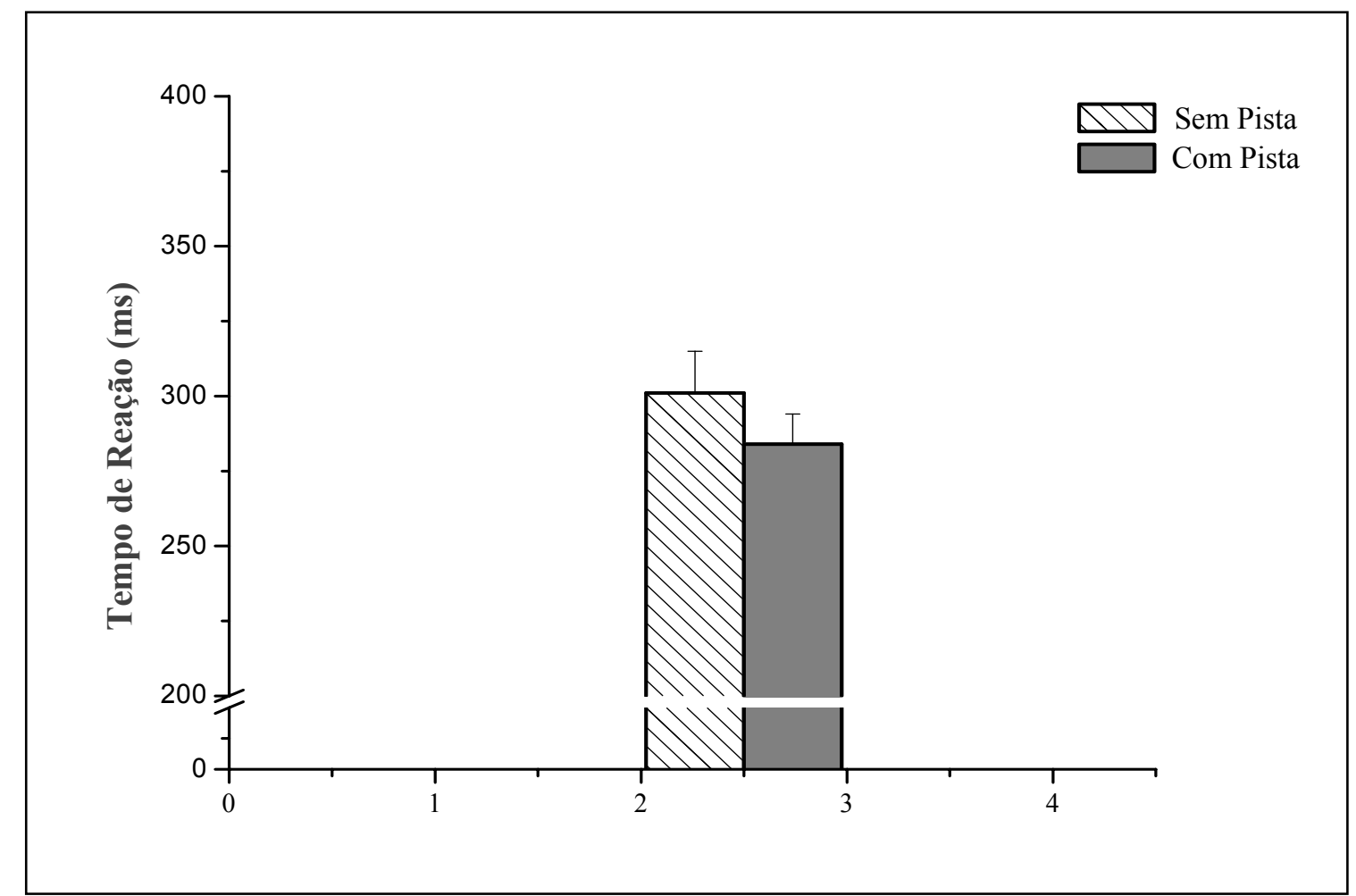

Figura 8.3 - Tempo de reação em milisegundos (média Łe.p.m.) para as condições sem pista e com pista.

Tabela 14: Total de erros de antecipação, comissão, omissão nas condições sem pista e com pista.

Tipo de erro

$\begin{array}{llr}\text { Antecipação } & \text { Sem pista } & 8 \\ & \text { Com pista } & 18 \\ \text { Alarme Falso } & \text { Sem pista } & 0 \\ & \text { Com pista } & 15 \\ \text { Omissão } & \text { Com pista } & 12 \\ & \text { Sem pista } & 4\end{array}$




\subsubsection{Discussão}

Surpreendentemente, ao invés do efeito inibitório, a pista provocou uma facilitação do processamento do estímulo-alvo. Isso significa que há outros fatores envolvidos no aparecimento da inibição observada no Experimento 1 e no Experimento 4, além do nível de preparação motora.

A facilitação seria o resultado da expectativa temporal e conseqüente orientação da atenção no tempo, que tende a ser mais intensa em tarefas de detecção (CORREA et al., 2006). Uma possibilidade para explicar os resultados deste experimento seria que ocorreu um

processo inibitório nesta tarefa, que foi antagonizado pela facilitação produzida pela orientação da atenção no tempo.

De qualquer forma, um processo inibitório poderia ainda assim ter ocorrido nesta tarefa. Seus efeitos teriam sido antagonizados pela facilitação provocada pela pista. 


\section{DISCUSSÃO GERAL}

\subsection{Efeitos da pista}

Neste trabalho, observamos um efeito inibitório da pista em uma tarefa vai/não-vai com estímulos centrais quando o intervalo de tempo entre os estímulos era constante (Experimento 1 e Experimento 4), mas não quando era variado ao longo da tarefa (Experimento 3). Isto significa que algum processo inibitório era desencadeado quando a pista indicava com precisão o momento de aparecimento do estímulo-alvo.

A primeira vista, esses resultados podem parecer surpreendentes. Na tarefa que utilizamos, a apresentação da pista poderia provocar diminuição do tempo de reação através de pelo menos dois processos: um aumento do alerta e uma orientação da atenção no tempo. O termo alerta se refere a um aumento geral de ativação do organismo, isto é, uma preparação inespecífica (CORREA et al., 2004; RAZ e BUHLE, 2006). A orientação da atenção no tempo geraria uma preparação específica, baseada na expectativa temporal (CORREA et al., 2004). A facilitação gerada pela apresentação da pista pode ser observada claramente na tarefa de detecção do Experimento 6.

Entretanto, no Experimento 1 e no Experimento 4 deste trabalho, ao invés dessa facilitação, houve um efeito inibitório da pista. Simultaneamente a processos que facilitariam a resposta ao estímulo-alvo, houve pelo menos um processo inibitório, que causou a lentificação da resposta a ele.

Se os estímulos são apresentados sempre na mesma posição, ocorre a orientação voluntária da atenção para o local da pista. Tanto a atenção voluntária (KLEIN e HANSEN, 1990; IVANOFF e KLEIN, 2004) quanto a orientação da atenção no tempo (CORREA et al., 2006) afetam o estágio decisional de processamento e gerariam um aumento no nível de preparação motora. Sendo assim, no Experimento 1 e no Experimento 4, houve um alto grau de preparação motora, que parece ser fundamental para o aparecimento do efeito inibitório da pista.

Se isso é verdade, a diminuição no nível de preparação motora faria com que esse efeito da pista não fosse mais observado ou diminuísse de magnitude. De fato, quando uma tarefa de escolha foi utilizada (Experimento 5), não houve efeitos significativos da pista no tempo de reação. Nesse tipo de tarefa, a resposta pode ser dada com a mão direita ou com a mão esquerda, dependendo do estímulo-alvo que for apresentado. Sendo assim, primeiramente o estímulo-alvo deve ser identificado para depois a resposta ser selecionada, o que levaria a um menor grau de preparação motora nesse tipo de tarefa em comparação 
às tarefas vai/não-vai.

Diversos autores têm proposto que mecanismos decisionais causariam a inibição de retorno. Entretanto, a maneira como essa questão é abordada e os processos inibitórios propostos pelos autores variam muito. Por exemplo, Klein e Taylor (1994) propuseram que a inibição de retorno resultaria de um viés em favor de novos locais do espaço e que surgiria em um mapa motor espacial que direciona a ação. Esse viés poderia ser devido a um aumento do critério para responder a estímulos apresentados na mesma posição da pista. Ajustes de critério de resposta mudam a proporção de erros e acertos em uma tarefa. Quanto maior o critério, maior o tempo de reação e menor o número de erros por alarme falso (PALMER, 1999).

Os resultados do trabalho de Ivanoff e Klein (2001) forneceram um apoio a essa proposta de que a inibição de retorno estaria associada a uma alteração de critério. Esses autores observaram um efeito inibitório da pista em uma tarefa vai/não-vai com estímulos centrais e periféricos. Os dados relativos à acurácia indicaram um aumento do critério quando pista e estímulo-alvo eram apresentados na mesma posição em comparação a quando eram apresentados em locais diferentes (estímulos periféricos) ou a pista não era apresentada (estímulos centrais). Entretanto, os dados sobre erros variam muito na literatura. A inibição de retorno pode ocorrer na ausência de mudança de critério (HANDY et al., 1999) e está algumas vezes associada a um aumento no número de erros quando pista e estímulo-alvo aparecem no mesmo local (CHEAL e CHASTAIN, 1999).

Com base na proposta de Klein e Taylor (1994), Van der Lubbe et al. (2005) sugeriram que se o nível inicial de preparação motora entre as tarefas difere, a inibição induzida pela pista também poderia ser diferente. Nas tarefas de detecção, a resposta já está selecionada e preparada antes da apresentação do estímulo-alvo. Por isso, a inibição engatilhada pela pista poderia surgir mais precocemente nesse tipo de tarefa. Essa seria a razão pela qual a inibição de retorno é observada tipicamente mais cedo em tarefas de deteç̧ão quando comparada às tarefas de discriminação.

A proposta de Van der Lubbe et al. (2005), poderia explicar os resultados obtidos no trabalho de Lupiáñez et al. (2001). Nesse estudo, os estímulos-alvo foram apresentados com freqüências diferentes dentro do mesmo bloco de tentativas. A pista facilitou o processamento dos estímulos-alvo pouco freqüentes ao mesmo tempo em que uma inibição de retorno foi observada para os estímulos-alvo muito freqüentes. Se um estímulo-alvo for apresentado muitas vezes durante um experimento, a resposta associada a ele também será 
muitas vezes executada. Esse repetição levaria a um alto nível de preparação da resposta (MILLER, 1998; IVANOFF e KLEIN, 2004), o que aceleraria o aparecimento da inibição de retorno. De fato, a inibição de retorno surgiu aos $100 \mathrm{~ms}$ para os estímulos muito freqüentes.

Ivanoff e Klein (2004) observaram que a inibição de retorno era maior quando um estímulo-alvo e a resposta a ele se repetiam com freqüência durante o teste, em comparação a quando a associação estímulo-resposta era pouco freqüente. Os tempos de reação são normalmente menores quando se responde muitas vezes a um mesmo estímulo, o que poderia ser atribuído à preparação da resposta a ele antes mesmo de seu aparecimento (MILLER, 1998). Essa interação entre a magnitude da inibição de retorno e o efeito de probabilidade estímulo-resposta sugere que eles afetam pelo menos um estágio de processamento em comum, o estágio decisional (KLEIN e HANSEN, 1990).

Embora estudos com potenciais relacionados a eventos (PRE) tenham contribuído muito para o entendimento dos mecanismos atencionais, poucos autores utilizaram essa técnica no estudo dos mecanismos decisionais da inibição de retorno (PRIME e WARD, 2006; VAN DER LUBBE et al., 2005; VAN DER LUBBE et al., 2006). O P1 é um componente do PRE medido no córtex extra-estriado, cuja amplitude aumenta com a modulação da atenção visual. Se a inibição de retorno envolve um atraso no retorno da atenção ao local em que a pista foi apresentada, a amplitude de P1 diminuiria em associação a esse fenômeno.

Já o LRP (lateralizaded readiness potential) se refere à medida da atividade cerebral gerada no córtex motor. O LRP pode ser medido em relação ao estímulo-alvo ou em relação à resposta. A latência do LRP em relação ao estímulo-alvo (target-locked LRP) constitui uma medida da duração do processo envolvido na avaliação do estímulo e na seleção da resposta. Similarmente, o intervalo entre o início do LRP relacionado à resposta e a resposta fornece uma medida da duração dos processos motores, isto é, planejamento motor e execução.

Alguns autores (PRIME e WARD, 2006; VAN DER LUBBE et al., 2005; VAN DER LUBBE et al., 2006) encontraram um atraso no momento de início do LRP relacionado ao estímulo-alvo em associação com a inibição de retorno, mas não do LRP relacionado à resposta. Esses resultados indicam que na inibição de retorno ocorre uma modulação de processos pré-motores, por exemplo, mecanismos decisionais. Uma pergunta pertinente seria se os resultados que são descritos como sendo devidos a 
mecanismos decisionais não seriam, na verdade, causados por uma alteração no estágio motor de processamento A ausência de modulação do LRP relacionado à resposta nesses estudos seria uma evidência de que os processos inibitórios devidos à inibição de retorno não interferem em mecanismos puramente motores.

Van der Lubbe et al. (2006) propuseram que a inibição de retorno apareceria tipicamente cedo em tarefas de detecção em função de uma inibição da resposta à pista. Com um alto grau de preparação motora em uma tarefa, o aparecimento de qualquer estímulo, incluindo a pista, poderia desencadear uma resposta (MAYLOR e HOCKEY, 1985; VAN DER LUBBE et al., 2006; PRIME e WARD, 2006). Entretanto, responder à pista levaria a um grande número de erros, o que afetaria o desempenho na tarefa. Por isso, a resposta à pista seria inibida. Essa inibição dificultaria a resposta ao estímulo-alvo, aumentando o tempo de reação (VAN DER LUBBE et al., 2006; PRIME e WARD, 2006).

Provavelmente, esse aumento do tempo de reação está associado à necessidade de a inibição ser primeiro vencida para que a resposta seja selecionada e executada (ARON et al, 2004; VAN DER LUBBE et al., 2006). Portanto, a resposta ao estímulo-alvo seria afetada pelos pós-efeitos da inibição da resposta à pista, que surgiria em um mapa motor espacial envolvido no controle das respostas manuais (KLEIN e TAYLOR, 1994; VAN DER LUBBE et al., 2006).

Se esse processo realmente ocorre, dependeria da semelhança entre pista e estímulo-alvo. Portanto, os resultados não seriam os mesmos se ambos os estímulos fossem visuais em comparação a uma tarefa em que a pista fosse auditiva e o estímulo-alvo, visual (VAN DER LUBBE et al., 2006). De fato, Van der Lubbe et al. (2006) observaram uma inibição de retorno precoce para a tarefa de detecção e uma facilitação para a de discriminação, utilizando valores de SOA a partir de $210 \mathrm{~ms}$, quando pista e estímulo-alvo eram visuais. No entanto, quanto a pista era auditiva, houve facilitação para ambas as tarefas. Além disso, a inibição de retorno na tarefa de detecção ocorreu em associação com um atraso no início do LRP relacionado à resposta.

Não acreditamos que a inibição da resposta à pista seja o único mecanismo decisional responsável pela inibição de retorno. A inibição de retorno ocorre em paradigmas em que são apresentados apenas estímulos-alvo (paradigma alvo-alvo), sem a presença de pistas (PRIME e WARD, 2006). De qualquer forma, os efeitos da inibição de retorno são maiores em paradigmas pista-alvo em relação a paradigmas alvo-alvo (TASSINARI et al., 2002), sugerindo que a inibição da resposta realmente contribua para a 
magnitude da inibição de retorno.

Os resultados de nosso estudo, em associação com as informações da literatura, sugerem que o nível de preparação motora é importante para o aparecimento do efeito inibitório da pista. No entanto, se o aparecimento dessa inibição depende apenas do nível de preparação motora na tarefa, ela deveria também ter sido observada na tarefa de deteç̧ão do Experimento 6. A inibição de retorno tem sido tipicamente observada mais cedo em tarefas de detecção que de discriminação com estímulos periféricos. Ao contrário, no nosso Experimento 6 houve uma clara facilitação.

Nas tarefas de detecção, o efeito de orientação da atenção no tempo seria mais intenso que nas tarefas de discriminação (CORREA et al., 2004). Uma possibilidade seria ocorreu um processo inibitório que foi antagonizado pela intensa facilitação produzida pela pista. Uma alternativa seria considerar que diferentes substratos neurais estariam envolvidos com os efeitos observados nas várias tarefas que utilizamos. Além disso, as tarefas detecção diferem das tarefas de discriminação, não só em relação às demandas perceptuais e ao nível inicial de preparação motora. Nas tarefas de detecção, haveria um menor critério, ou seja, menos informação seria necessária para desencadear a resposta. Essa diferença de critério poderia também ter influenciado os resultados. Por último, as tarefas de detecção e de discriminação apresentam, pelo menos em parte, diferentes substratos neurais.

Em 1992, Goodale e Milner propuseram uma divisão de trabalho entre duas vias paralelas do córtex visual de primatas. A via dorsal se projeta do córtex visual primário para o córtex parietal posterior e forneceria um controle flexível dos módulos subcorticais visuomotores. A via ventral se projeta de V1 para o lobo temporal e proveria uma rica e detalhada representação do mundo, necessária para operações cognitivas, como reconhecimento e identificação. Desde então, inúmeras evidências tem dado suporte a sua proposta desses autores. Usando uma variedade de tarefas e respostas, outros pesquisadores têm mostrado importantes diferenças entre a percepção de estímulos visuais e o controle das ações direcionadas a um estímulo (DECO e ROLLS, 2005).

Os seres humanos e demais primatas se baseiam principalmente na visão para controlar seu comportamento e, consequentemente, as informações visuais são particularmente importantes para tomar uma decisão (OPRIS e BRUCE, 2005). A existência de diferentes mecanismos envolvidos com o processamento da informação nessas duas vias visuais, poderia ter um grande impacto nos resultados obtidos nas tarefas 
de tempo de reação.

A grande maioria dos estudos comentados neste trabalho envolveu estímulos periféricos, com exceção de apenas dois trabalhos (IVANOFF e KLEIN, 2001; MAYLOR e HOCKEY, 19985), que utilizaram condições em que pista e estímulo-alvo eram apresentados centralmente. Entretanto, mecanismos decisionais parecem estar envolvidos nos efeitos inibitórios da pista, tanto com estímulos centrais quanto com estímulos periféricos. Ivanoff e Klein (2001) realizaram uma tarefa vai/não-vai com SOAs de 465 e $1050 \mathrm{~ms}$ e observaram um efeito inibitório cuja magnitude diminuía com o tempo. Esses autores propuseram que esse efeito se deveria a um aumento do critério de resposta quando a pista era apresentada antes do estímulo-alvo, em comparação a quando não era apresentada. Maylor e Hockey (1985) observaram o efeito inibitório da pista em uma tarefa de detecção em que o SOA era sempre 900 ms, resultado que foi atribuído a uma inibição da resposta à pista.

A via dorsal estaria mais envolvida com a detecção de estímulos brevemente apresentados no campo visual. Enquanto isso, a identificação dos estímulos-alvo das tarefas de discriminação envolveria predominantemente a via ventral. Isso ocorreria principalmente quando a tarefa de discriminação envolve estímulos apresentados sempre no centro do campo visual, como as tarefas vai/não-vai que utilizamos neste trabalho. Se vias diferentes estão envolvidas com as tarefas de detecção e discriminação, não necessariamente os mesmos mecanismos estariam envolvidos com os resultados obtidos nessas tarefas ou, pelo menos, não na mesma magnitude.

Os efeitos inibitórios da pista visual em tarefas de tempo de reação podem ser devidos a diferentes mecanismos. A execução de um comportamento envolve um balanço entre processos excitatórios e inibitórios. O controle inibitório seria uma importante função no controle executivo e estaria acometido em patologias como a hiperatividade, a desordem obsessivo-compulsiva ou a síndrome de Tourette (ARON et al., 2004). Por exemplo, quando uma resposta é executada, as respostas concorrentes devem ser inibidas.

O tempo de reação quando estímulo-alvo e mão de resposta são espacialmente correspondentes (por exemplo, resposta com mão direita e estímulo-alvo apresentado à direita) pode ser menor em comparação a quando não existe essa correspondência. Essa diferença recebe o nome de efeito de compatibilidade estímulo-resposta e ocorre apenas quando respostas concorrentes devem ser inibidas. Isso significa que não é normalmente encontrado em tarefas de tempo de reação simples, ou seja, quando se responde ao 
aparecimento do estímulo-alvo sempre com a mesma mão. O efeito de compatibilidade estímulo-resposta surgiria de uma tendência natural de responder na mesma direção do evento de interesse (IVANOFF e KLEIN, 2001).

No trabalho de Ivanoff e Klein (2001), quando uma das mãos foi simplesmente posicionada na chave de resposta, enquanto se respondia durante o teste efetivamente apenas com a outra mão, observou-se não só um maior efeito de compatibilidade, como também um aumento na magnitude da inibição de retorno. Esses resultados sugerem que a inibição de respostas inapropriadas e a inibição de retorno apresentam mecanismos em comum.

Não se sabe ainda a relação entre essas inibições comportamentais e outras formas de inibição, como a inibição de retorno. A inibição de retorno descrita por Posner e Cohen (1984) poderia ser apenas uma dentre muitas outras formas de inibição, que tornariam mais eficiente a interação com o ambiente. Não se conhece ainda todos os mecanismos subjacentes a esses processos inibitórios ou o quanto os mesmos mecanismos são compartilhados por diferentes processos.

\subsection{Mecanismos neurais}

Os estudos sobre a inibição de retorno forneceram evidências de que a pista pode agir em inúmeros estágios de processamento, inclusive simultaneamente (LUPIÁÑEZ et al., 2005). Entretanto, muito pouco se fala na literatura da área sobre os mecanismos neurais subjacentes a esses efeitos da pista, principalmente em relação aos processos decisionais. O objetivo desta seção é propor mecanismos neurais que pudessem explicar os resultados obtidos neste trabalho. Antes disso, será apresentada uma revisão das principais estruturas envolvidas na elaboração dos comportamentos dirigidos a um objetivo.

\subsubsection{Córtex pré-frontal e controle executivo}

O córtex pré-frontal está no ponto mais alto da hierarquia motora. Participa de todos os aspectos da adaptação do organismo ao ambiente e apresenta um papel fundamental no chamado controle executivo (KROPOTOV e ETLINGER, 1999; FUSTER, 2000; FUNAHASHI, 2001; DECO e ROLLS, 2005; OPRIS e BRUCE, 2005). O termo "executivo" está relacionado à elaboração de comportamentos, que vão além do movimento propriamente dito. As funções executivas ou funções cognitivas de alta ordem incluem processos como raciocínio, julgamento, tomada de decisão e planejamento 
(KROPOTOV e ETLINGER, 1999; FUNAHASHI, 2001).

Os mecanismos do córtex pré-frontal permitem que percepção seja transformada em comportamento, mesmo em função de informações ambientais que não estão mais presentes. Informações passadas podem ser associadas a comportamentos futuros através da manutenção da representação de informações relevantes ativa, acessível e manipulável. Esse tipo de memória de curto prazo recebe o nome de memória operacional (DECO e ROLLS, 2006; FUNAHASHI, 2001; COURTNEY, 2004; AWH et al., 2006). A memória operacional permite que a ligação entre estímulos sensoriais e respostas seja mantida através do tempo (FUSTER, 2000). Em nosso trabalho, as representações da linha, da cruz ou do anel precisam ser mantidas ativas, de modo que esses estímulos sejam reconhecidos. Do mesmo modo, a representação da resposta a ser executada, em associação a um dos estímulos e não ao outro, deve ser mantida disponível.

A memória operacional parece estar organizada de forma domínio-específico nas regiões mais posteriores do córtex pré-frontal dorsolateral. A informação verbal e em relação ao objeto chegaria principalmente às áreas BA 45 e BA 47, enquanto a informação espacial chegaria à área BA 8. A atividade em regiões mais anteriores (BA 46, 9 e 10) frequentemente não diferencia as características dos estímulos (COURTNEY, 2004).

Além dessa organização da memória operacional de acordo com os atributos do estímulo, parece existir um outro padrão de organização dentro do córtex pré-frontal, dessa vez hierárquico. Áreas progressivamente mais anteriores do córtex pré-frontal dorsolateral contêm representações cada vez mais complexas, representações mais abstratas e integradas de toda a informação disponível (COURTNEY, 2004). Nessas regiões estaria representada a informação, por exemplo, de que a resposta deve ser executada o mais rapidamente possível quando aparecer a linha e evitada quando aparecer o anel.

Essas representações geram um viés nos resultados da competição entre representações dentro e fora do córtex pré-frontal (COURTNEY, 2004; DECO e ROLLS, 2005; FUNAHASHI, 2001; FUSTER, 2004). O córtex pré-frontal dorsolateral, aproximadamente a área $\mathrm{BA} 46$, representaria os requerimentos da tarefa atual e influenciaria as representações no córtex parietal posterior e outras áreas perceptuais, modulando as interações entre essas regiões (DECO e ROLLS, 2005). A representação da linha ou da cruz estaria mais ativa do que a representação do anel que permanece na tela durante toda a tarefa e dentro do qual os estímulos-alvos são apresentados.

O córtex pré-frontal dorsolateral apresenta conexões anatômicas com várias 
regiões corticais e subcorticais, especialmente áreas de associação sensorial e o sistema límbico. Através dessas conexões o córtex pré-frontal dorsolateral poderia influenciar as entradas provenientes de informações, sensorial, motora, emocionais tanto quanto a informação armazenada na memória de longo prazo (COURTNEY, 2004; DECO e ROLLS, 2005; FUNAHASHI, 2001).

Neurônios do córtex pré-frontal, assim como do córtex parietal posterior e dos núcleos da base, são modulados pela expectativa de recompensa. Muitos neurônios do córtex pré-frontal relacionadas à memória operacional aumentam o nível de atividade quando há expectativa de recompensa para a tarefa. Uma fonte importante desses sinais seriam neurônios dopaminérgicos localizados na área tegmental ventral (VTA) e parte compacta da substância negra $(\mathrm{SNc})$, que apresentam conexões com diversas áreas, incluindo conexões recíprocas com a amígdala basolateral e córtex pré-frontal (KROPOTOV e ETLINGER, 1999). Quando colegas de classe participam do mesmo experimento e comentam entre si os resultados, pode se iniciar uma competição entre eles. O desejo de ter um melhor desempenho que os outros pode aumentar a motivação para realizar bem o experimento.

Um modelo proposto por Deco e Rolls (2005) fornece um exemplo dos efeitos do córtex frontal em outras áreas. Segundo o Biased competition model, os vários estímulos do campo visual ativam populações de neurônios do córtex visual, que interagem de modo competitivo. Sinais de fora do campo visual gerariam um viés nessa competição, favorecendo os estímulos para os quais a atenção está direcionada (DRIVER e FRITH, 2000). Segundo Deco e Rolls (2005), a parte da região BA 46 dorsal ao sulco principal (d46) geraria um viés na via dorsal. Da mesma forma, um viés na via ventral seria gerado pela área v46, ventral a esse mesmo sulco. As vias ventral e dorsal interagiriam, principalmente em V1.

A atenção, assim como a memória operacional, tem sido apontada por muitos autores como uma das funções do controle executivo (COURTNEY, 2004; FUNAHASHI, 2001; HOPFINGER et al., 2000). Nesse caso os autores se referem principalmente à chamada atenção executiva. Alguns autores consideram atenção executiva qualquer tipo de controle descendente. Neste caso, a orientação endógena da atenção estaria aqui incluída. Outros autores entendem atenção executiva como o monitoramento e a resolução de conflitos entre o funcionamento de diversas áreas neurais. Estaria relacionada ao planejamento, tomada de decisão, detecção de erros; seria importante para tarefas novas ou 
não muito bem aprendidas, superação de respostas automáticas, condições consideradas difíceis ou perigosas (RAZ e BUHLE, 2006). Essas são condições em que na linguagem popular seria necessário "prestar atenção".

Haveria uma orientação endógena da atenção para a região central do campo visual em nossos experimentos. Da mesma forma, a atenção estaria orientada para as características dos estímulos relevantes para a tarefa. Como o momento de aparecimento do estímulo é conhecido, haveria orientação da atenção no tempo de forma a favorecer a resposta ao estímulo-alvo. Para respostas ao estímulo-alvo negativo é necessário que se "preste atenção à tarefa", pelo menos no início. O processo conhecido como atenção executiva monitoraria os erros e o desempenho em geral na tarefa (COURTNEY, 2004; DECO e ROLLS, 2005; DUCAN e OWEN, 2000; FUNAHASHI, 2001).

\subsubsection{Decisão e Seleção de respostas}

Animais com sistemas nervosos mais simples têm uma variedade restrita de comportamentos. Enquanto isso, o homem é capaz de produzir uma grande diversidade de comportamentos complexos. A habilidade de decidir o comportamento mais adequado em determinado contexto ambiental pode significar a própria sobrevivência e depende de uma série de processos.

Para a tomada de decisão, evidências sensoriais devem ser acumuladas. Existem evidências de que o córtex pré-frontal estaria envolvido na integração de evidências sensoriais necessárias para a tomada de decisão, seu acúmulo através do tempo, tanto na via ventral (HEEKEREM, 2004) quanto na via dorsal (NEWSOME et al., 2002). No trabalho de Newsome et al., neurônios da área V5 de macacos apresentavam maior atividade conforme o movimento na direção para a qual eram seletivos se tornava mais evidente. Quanto maior a atividade das células seletivas à direção do movimento da área V5 em macacos ou da área V4 em humanos (HEEKEREM, 2004), mais provável a decisão na direção preferida por elas. Esses resultados sugerem que a evidência sensorial é acumulada até o limiar de decisão ser alcançado. A quantidade de evidências necessárias para desencadear uma resposta tem recebido o nome de critério. Como já foi dito, a expectativa de recompensa pode afetar a resposta de neurônios do córtex pré-frontal. A motivação de vencer os amigos poderia diminuir o critério de resposta. Nesse caso, a quantidade de informação acumulada sobre o estímulo-alvo necessária para desencadear a resposta diminuiria. $\mathrm{O}$ voluntário seria mais rápido na realização da tarefa, mas cometeria 
mais erros.

$\mathrm{O}$ córtex pré-frontal dorsolateral representa as regras e objetivos da tarefa. $\mathrm{O}$ conhecimento sobre a situação permitiria avaliar se uma ação em resposta ao estímulo-alvo apresentado seria ou não apropriada. A atividade do córtex pré-frontal ventro-lateral seria importante na avaliação do estímulo apresentado como sendo ou não o alvo (COURTNEY, 2004; DECO e ROLLS, 2005; DUCAN e OWEN, 2000; FUNAHASHI, 2001).

A região do giro frontal superior parece ter um papel central na codificação de conflito de respostas e estar envolvido na mudança dos ajustes relacionados a uma tarefa, principalmente quando há mudanças na resposta selecionada $\mathrm{O}$ córtex cingulado anterior provavelmente é responsável por monitorar os erros cometidos em uma ação e parece fazer parte de um sistema para codificar se uma ação deve ser realizada, dado o valor do resultado esperado e o custo para realizá-la (RORIE e NEWSOME, 2005; RUSHWORTH et al., 2004). Se os erros cometidos porque a resposta está sendo desencadeada pela apresentação da pista são percebidos, a estratégia comportamental pode ser modificada. Inibir a resposta à pista seria uma forma de melhorar o desempenho na tarefa.

Após a decisão ser tomada, a resposta mais adequada precisa ser selecionada. Os processos de seleção de resposta não produzem uma percepção ou ato motor em si, mas capacitam os sujeitos para selecionar um movimento de todo o repertório possível. A seleção de resposta envolveria circuitos dos quais fazem parte os núcleos da base, tálamo e regiões corticais, também importantes nas diversas formas de atenção e funções cognitivas em geral (KROPOTOV e ETLINGER, 1999; OPRIS e BRUCE, 2005).

$\mathrm{Na}$ seleção da resposta mais apropriada, a informação com maior peso ou "saliência" face às informações disponíveis vence e é executada. Os núcleos da base teriam os mecanismos necessários para realizar essa seleção com base nas aferências que chegam a eles de todas as partes do córtex cerebral e enviar, via tálamo, informações para o córtex pré-frontal e para os córtices pré-motor e motor primário. Assim, poderiam selecionar as diversas entradas competidoras dos córtices frontal, parietal e temporal (KROPOTOV e ETLINGER, 1999; OPRIS e BRUCE, 2005).

Existe uma rede de circuitos em paralelo envolvendo núcleos da base e córtex préfrontal, cada circuito se focando em uma diferente porção do córtex de associação frontal. As funções desses diferentes circuitos parecem ser diferentes uma da outra e englobar desde o controle motor puro até o controle cognitivo. O córtex pré-frontal envia informações ao neoestriado. A informação é processada no circuito pálido-nigro- 
subtalâmico e a ativação diferencial de uma resposta volta ao córtex, via tálamo (KROPOTOV e ETLINGER, 1999; OPRIS e BRUCE, 2005).

Após a integração de todas essas informações nos circuitos pálido-nigrosubtalâmicos, a informação sobre a resposta com a representação mais ativa seria enviada para o córtices pré-frontal, pré-motor e motor primário (KROPOTOV e ETLINGER, 1999; OPRIS e BRUCE, 2005). Entretanto, além de a resposta adequada ser selecionada, respostas concorrentes e inapropriadas precisam ser inibidas.

\subsubsection{Córtex pré-frontal e controle inibitório}

Todo comportamento requer um controle fino entre processos excitatórios e inibitórios (ARON et al., 2004; OPRIS e BRUCE, 2005). Além de a resposta adequada ser selecionada, respostas concorrentes devem ser inibidas. Por exemplo, se a resposta com a mão direita é selecionada, a resposta com a mão esquerda deve ser inibida. $\mathrm{O}$ controle inibitório estaria também envolvido na supressão de memórias inapropriadas, na resolução de interferências entre tarefas realizadas simultaneamente e na mudança de ajustes na tarefa (ARON et al., 2004; OPRIS e BRUCE, 2005).

O controle inibitório é testado frequentemente usando paradigmas do tipo vai/nãovai (RUBIA et al., 2001; ARON et al., 2004). Pode-se inferir que pacientes afetados por patologias como a desordem obsessivo-compulsiva cometeriam mais erros em nossas tarefas de tempo de reação. Em estudos de neuroimagem funcional o córtex pré-frontal é consistentemente ativado nesse tipo de tarefa.

Um possível mecanismo pelo qual o córtex pré-frontal exerceria o controle inibitório seria a estimulação do núcleo subtalâmico, que inibe as projeções tálamocorticais via globo pálido interno (ARON et al., 2004). Ainda não se sabe como as inibições mediadas pelo córtex frontal interagem com outras formas de inibição, como a inibição de retorno.

\subsection{Efeito da Forma dos Estímulos-Alvo}

Nos três primeiros experimentos deste trabalho, os voluntários foram divididos em dois grupos conforme a forma do estímulo-alvo positivo: linha ou cruz. Em nenhum desses experimentos encontramos diferenças significativas nos tempos de reação para esses diferentes estímulos-alvo. Entretanto, os tempos de reação para a cruz são notadamente mais baixos que para a linha. 
Comparamos os resultados desses dois estímulos-alvo em função de resultados prévios de nosso laboratório. No trabalho de Azevedo et al. (2000), um anel cinza foi usado como pista visual em uma tarefa de tempo de reação vai/não-vai em que os estímulos eram apresentados na periferia do campo visual. Quando o estímulo-alvo positivo foi uma linha vertical no interior de um anel, o anel cinza causou uma facilitação. No entanto, quando o estímulo-alvo positivo foi uma cruz no interior do anel, nenhum efeito significativo da pista foi observado. O estímulo-alvo negativo era constituído de dois anéis concêntricos em ambos os casos. O valor de SOA era sempre $100 \mathrm{~ms}$.

Neste trabalho, optamos por estímulos-alvo um pouco diferentes daqueles utilizados por Azevedo et al. (2001), mas utilizados com freqüência na literatura. Em vez de estímulos-alvo compostos por um anel e outro elemento em seu interior, usamos apenas a cruz ou a linha. $\mathrm{O}$ anel foi apresentado na tela desde o início da tentativa, marcando a posição de aparecimento dos estímulos-alvo.

Azevedo et al. (2001) propuseram que o anel cinza teria mascarado a cruz no interior do anel. A ocorrência desse mascaramento anterógrado da cruz antagonizaria os efeitos da orientação da atenção para o local da pista. Por isso, a facilitação apareceu apenas para a linha. Entretanto, Fuga (2002) não encontraram evidências consistentes de que os resultados desses autores se devessem mesmo a um mascaramento.

Uma outra possibilidade seria considerar que a cruz no interior do anel é mais discriminável que a linha. $\mathrm{O}$ uso de posição marcada em nossos experimentos pode ter diminuído a incerteza em relação ao local de aparecimento do estímulo-alvo, o que tornaria mais fácil a tarefa. Se a linha é menos discriminável que a cruz, ficaria mais fácil identifica-la nessas condições. Quanto mais fácil a tarefa, menor seria a orientação da atenção para o local da pista (KLEIN, 2000). Sendo assim, poderia haver uma menor facilitação para a linha, mas não faria sentido o surgimento de uma facilitação para a cruz, justamente quando sua discriminação teria se tornado ainda mais fácil.

Uma outra possibilidade seria que houve realmente um mascaramento anterógrado para a cruz no trabalho de Azevedo et al. (2001). Com a mudança nas características dos estímulos, esse mascaramento deixou de ocorrer.

No Experimento 3, no SOA de $267 \mathrm{~ms}$, houve facilitação para a cruz e inibição para a linha. A emergência dessa inibição apenas em 267 ms lembra os cursos temporais vistos tipicamente para a inibição de retorno em tarefas de detecção com estímulos periféricos (SAMUEL e KATT, 2003). Se a cruz é mais discriminável que a linha, o 
critério de resposta seria menor para a cruz, ou seja, menos informação seria necessária para que a resposta a ela fosse selecionada e executada. Além disso, podemos dizer que nas tarefas de detecção o critério de resposta seria menor que nas tarefas de discriminação. Entretanto, a inibição de retorno surge tradicionalmente em SOAs curtos nas tarefas de detecção, mas o efeito inibitório da pista não apareceu em 267 ms para a cruz, apenas para a linha. Esse raciocínio levaria à conclusão de que a linha seria mais discriminável que a cruz, o que iria contra os menores tempos de reação para esse último estímulo. 


\section{Conclusão}

Observamos em uma tarefa vai/não-vai com estímulos centrais um efeito inibitório da pista, que depende de um alto nível de preparação motora na tarefa. A apresentação da pista iniciaria um processo inibitório que afetaria mecanismos decisionais. Um mecanismo possível seria a ocorrência de uma inibição da resposta à pista, o que levaria a um atraso na resposta ao estímulo-alvo.

Nossos resultados sugerem que os efeitos inibitórios da pista descritos para estímulos periféricos e os efeitos inibitórios para estímulos centrais podem apresentar mecanismos semelhantes, mas não idênticos. As vias ventral e dorsal estariam envolvidas de modo diferente com os processos que levariam aos efeitos inibitórios da pista. Entretanto, diferenciar a contribuição de cada uma delas para os efeitos da pista descritos na literatura sobre inibição de retorno requer um estudo aprofundado da questão e seria um tópico interessante para pesquisas futuras.

\section{REFERÊNCIAS BIBLIOGRÁFICAS}

ARON, A.R.; ROBBINS, T.W.; POLDRACK, R.A. Inhibition and the right inferior frontal cortex. Trends in Cognitive Science, v.8. n.4, p.201-208, 2004.

ARNOTT, S.R., PRATT, J.; SHORE, D.I.; ALAIN, C. Attentional set modulates visual areas: an event-related potential study of attentional capture. Cognitive Brain Research, n.12, p.383-395, 2001.

AWH, E.; VOGEL, E,K.;OH, SH. Interactions between attention and working memory. Neuroscience, n.139, p.201-208,2006

AZEVEDO, E.L.; SQUELLA, S. A. F.; RIBEIRO-DO-VALLE, L. E. The early facilitatory effect of a peripheral spatially no informative prime stimulus depends on target stimulus features. Brazilian Journal of Medical and Biological Research, V.34, p. 803$813,2001$.

BREITMEYER, B. G. Visual masking: An integrative approach. New York: Oxford University Press, 1984.

CASTEl, A.D., PRATT, J., CHASTEEN, A.L. SCIALFA, C. T. Examining Task Difficulty and the Time Course of Inhibition of Return:Detecting Perceptually Degraded Targets. Canadian Journal of Experimental Psychology, v.59, n.2, p. 90-98, 2005. 
CORBETTA, M.; SHULMAN, G. L.; Control of goal-directed and stimulus driven attention in the brain. Natures Review Neuroscience, v.3, p. 201-215, 2002.

CORRÊA, A.; LUPIÃNEZ, J.; MILLIKEN, B.; TUDELA, P. Endogenous temporal orienting of attention in detection and discrimination tasks. Perception \& Psychophysics, v.66, n.2, p. 264-278, 2004.

CORRÊA, A.; LUPIÃNEZ, J.; TUDELA, P. The attentional mechanism of temporal orienting: determinants and attributes. Experimental Brain Research, n.16, p.58-68, 2006.

COULL, J. T. Neural correlates of attention and arousal insights from electrophysiology, functional neuroimaging and psychopharmacology. Progress in Neurobiology, v.55, p. 343-361, 1998.

* De acordo com:

CASSOCLACÃO BRASLEIRA DE NORMAS TÉCNICAS.NBR 6023: representation in working memory. Cognitive, Affective \& Behavioral Neuroscience, v.4, n.4, p.501-516, 2004

DECO, G; ROLLS, E.T.; Attention, short-term memory, and action selection: A unifying theory. Progress in Neurobiology, n.76, p.236-256, 2005.

DESIMONE, R.; DUNCAM, J. Neural mechanisms of selective visual attention. Annual Review Neuroscience, v.18, p.193-222, 1995.

DOSHER, B. A; LU, Z.-L. Mechanisms of perceptual attention in precuing of location.Vision Research, v. 40, p. 1269-1292, 2000.

DRIVER, J.; FRITH, C. Shifting baselines in attention research. Nature Reviews Neuroscience, v. 1, p.343-351, 2000.

ERICHSEM, C. W.; COLLINS, J. F. Reinterpretation of one form of backward and forward mask in visual perception. Journal of Experimental Psychology, v. 70, p.343$351,1965$.

FOLK. C. L. REMINGTON, R.W. JOHNSTON, J. C. Involuntary covert orienting is contingent on attentional control setting. Journal of Experimental Psychology: Human Perception and Performance, n. 18, p.1030-1044, 1992. 
FUGA, N.B. A Influência da atenção e do mascaramento anterógrado no tempo de reação. Dissertação (Mestrado). Instituto de Ciências Biomédicas da Universidade de São Paulo, 2002.

FUSTER, J.M. Executive frontal functions. Experimental Brains Research, n.133, p. 66$70,2000$.

FUSTER, J.M. Upper processing stages of the perception-action cycle. Trends in cognitive sciences, v.8, n.4, 2004.

FUNAHASHI, S. Neuronal mechanisms of executive control by the prefrontal cortex. Neuroscience research, n.39, p.147-165, 2001.

GESCHEIDER, G. A.; The theory of Signal Detection. In: Psychophysics: The Fundamentals. New Jersey: Lawrence Erlbaum Associates, 1999, p.105-375.

GOODALE, M. A.; MILLER, A.D. Separate visual pathways for perception and action. Trends in Neuroscience, n.15, p.20-25, 1992.

GÓMEZ, C. M.; VAQUEIRO, E.; VÁSQUEZ, M.; GONZÁ-LEZ-ROSA, J. J.; CARDOSO, M. J. Alternate-response preparation in a visuomotor serial task. Journal of Motor Behavior, v.37, n. 2, p. 127-134, 2005.

HEEKEREN, H. R. A general mechanism for perceptual decision-making in the human brain. Nature, n.431, p.859-862, 2004.

HOPFINGER, J.B.; BUONOCORE, M. H.; MANGUN, G.R. The neural mechanisms of top-down attentional control. Nature Neuroscience, v.3, n.3, 2000.

IVANOFF, J.; KLEIN, R.M. The presence of a nonresponding effector increases inhibition of return. Phychonomic Bulletin \& Review, v.8, n.2. p. 307-314, 2001.

IVANOFF, J.; KLEIN, R.M. Inhibition of return interacts with the Simon effect: An Omnibus analysis and its implications. Perception \& Psychophysics. v. 64, n.2, p.318$327,2002$.

IVANOFF, J.; KLEIN, R.M. Stimulus-response probability and inhibition of return, Psychonomics Bulletin \& Review, v.11, n.3, 542-550, 2004.

JONIDES, J. Voluntary versus automatic control over the mind's eye's movement, In: LONG, J.; BADDELEY, A. (Ed). Attention and performance, Hillsdale: Erlbaum, 1981. P. 187-203, 1981. 
KLAPP, S. T. Motor response programming during simple and choice reaction time: the role of practice. Journal of Experimental Psychology: Human Perception and Performance, v.21, n.5, p.567-577, 1995.

KANWISHER, N.; WOJCIULIK, E. Visual Attention: Insights from Brain Imaging. Nature Reviews - Neuroscience, v.1, 2000.

KLEIN, R. M. Inhibitory tagging system facilitates visual search. Nature, v. 334, p. 430$31,1988$.

KLEIN, R. M. Inhibition of return. Trends in Cognitive Sciences, v. 4, p. 138-147, 2000.

KLEIN, R.M.; TAYLOR, T. L. Categories of cognitive inhibition, with reference to attention. In: DAGENBACH, D.; CARR, T. H., (Ed). Inhibitory processes in attention, memory, and language. Academic Press, 1994, p. 113-150.

KROPOTOV, J.D.; ETLINGER, S. C. Selection of actions in the basal gangliathalamocortical circuits: review and model. International journal of Psychophysiology, n.31. p.197-217, 1999.

LAMBERT, A.; HOCKEY, R. Peripheral visual changes and spatial attention. Acta Psychologica, v. 76, p. 149-163, 1991.

LOGAN, G.D. Cumulative progress in formal theories of attention. Annual Review Pshychology, v.55, p.207-234, 2004.

IVANOFF, J.; KLEIN, R. M. The Presence of a Nonresponding Effector Increases Inhibition of Return. Psychonomic Bulletin \& Review, v.8, n.2, p. 307-314, 2001.

IVANOFF, J.; KLEIN, R. M. Inhibition of Return Interacts With The Simon Effect: An Omnibus Analysis and Its Implications. Perception \& Psychophysics. v. 64, n.2, p. 318 $327,2000$.

IVANOFF, J.; KLEIN, R. M. Stimulus-response Probability and Inhibition of Return. Psychonomic Bulletin \& Review. v.11, n.3, p. 542-550, 2004

LUCK, S. J.; WOODMAN, G. F.; VOGEL, E. K. Event-related Potential Studies of Attention. Trends in Cognitive Sciences, v. 4, n. 11, 2000.

LUPIÁÑEZ, J. Does inhibition of return occur in discrimination tasks? Yes, it does, but later. Percept. Psychophys., v. 59, p.1241-1423, 1997.

LUPIÁÑEZ, J. WEAVER, B.; TIPPER, S. P.; MADRID, E. On the strategic modulation of the time course of facilitation and inhibition of return. Quartely Journal of Experimental Psychology, v.54A, p.753-773, 2001. 
LUPIÁÑEZ, J. RUZ, M.; MILLIKEN, B. The manifestation of attentional capture: facilitation or IOR depending on task demands. Psychological Research., 2005.

MAYLOR, E.; HOCKEY, R. Inhibitory component of externally controlled covert orienting in visual space. Journal of Experimental Psychology and Human Perception and Performance, v. 11, p. 777-787, 1985.

MACMILlan, N. A.; CREELMAN, C. D. Detection theory: A user's guide. 2. ed. Mahwah: Lawrence Erlbaum Associates, 2005. 492 p.

MULLER, H. J.; FINDLAY, J. M. Sensitivity and criterion effects in the spatial cueing of visual attention. Perception and Psychophysics, v. 42, n. 4, p. 383-399, 1987.

NAKAYAMA, K.; MACKEBEN, M. Sustained and transient components o focal visual attention. Vision Research, v. 29, p. 1631-1647, 1989.

OLDFIELD, R. C. The assessment and analysis of handedness: The Edinburgh Inventory. Neuropsychologia, v. 9, p. 97-113, 1971.

OPRIS, I.; BRUCE, C.J. Neural circuitry of judgment and decision mechanisms. Brain Research Reviews, n. 48, p.509-526, 2005.

OTA, D. K.; RIBEIRO DO VALLE, L.E. Evolução temporal do mascaramento visual anterógrado em humanos. In: Reunião Anual da Federação de Sociedades de Biologia Experimental - FeSBE, XVI, 2001, Caxambu, Resumo, Caxambu: Federação de Sociedades de Biologia Experimental, 2001, p. 16.

RAZ, A.; BUHLE, J. Typologies of attentional networks. Nature Review Neuroscience, v.7, p.367-379, 2000

REYNOLDS, J. H.; PASTERNAK, T, DEMINONE, R. Attention increases sensitivity of V4 neurons. Neuron, v.26, p.703-714, 2000.

PALMER, S. E. Visual selection: Eye Movements and Attention. In: VISION SCIENCE. Massachusetts: Massachusetts Institute of Technology, 1999.

PALMER, J.; HUK, A. C.; SHADLEN, M. N. The effect of stimulus strength on the speed and accuracy of a perceptual decision. Journal of Vision, v. 5, p. 376-404, 2005.

POSNER, M.I. Orienting of attention. Quartely Journal of Experimental Psychology, v.32, p.3-25, 1980. 
POSNER, M. I.; COHEN, Y. Components of visual orienting. In: BOUMA, H.; BOUWHUIS, G.G. (Ed). Attention and Performance. Hillsdale: Erlbaum. 1984. p.531556.

PRIME, D. J.; WARD, L. M. Inhibition of return from stimulus to response. Psychological. Science. v.15, p.272-276, 2004.

SAMUEL, A. G.; KAT, D. Inhibition of return: a graphical meta-analysis of its time course and an empirical test of its temporal and spatial properties. Psychonomic Bulletin \& Review, v. 10, n. 4, p.897-906, 2003.

RAFAL, R. D. Saccade preparation inhibits reorienting to recently attended locations. J. Exp. Psycho. Hum. Percept. Perform., v. 15, p. 673-685, 1989.

TASSINARI, G.; AGLIOTI, S.; CHELAZZI, L.; PERU, A.; BERLUCHI, G. Do peripheral non-informative cues induce early facilitation of Target Detection? Vision Research, v.34, n.2, p. 174-189, 1994.

THEEUWES, J. Exogenous and endogenous control of attention: the effect of visual onsets and offsets. Perception and Psychophysics, v. 49, p. 83-90,1991.

RORIE, A.E.; NEWSOME, W.T.; A general mechanism for decision-making in the human brain? Trends in Cognitive Sciences, v. 9, n.2, 2005.

RUBIA, K; RUSSEL, T. OVERMEYER, S. BRAMMER, M.J.; BULLMORE, E.T. SHARMA, T.; SIMMONS, A.; WILLIANS, S.C.R.; GIAMPIETRO, V.; ANDREW C.M.; TAYLOR, E. Mapping motor inhibition: conjunctive brain activations across different versions of go/no-go and Stop tasks. Neuroimage, n.13, p.250-261, 2001.

RUSHWORTH, M. F. S.; PASSINGHAM, R. E.; NOBRE, A. C. Components of switching intentional set. Journal of Cognitive Neuroscience, v. 14, n. 8, p. 1139-1150, 2002.

RUSHWORTH, M.F.S.; WALTON, M.E. KENNERLEY, S.W. BANNERMAN, D.M. Action sets and decisions in the medial frontal cortex. Trends in cognitive sciences, v.8, n.9, 2004

RUSHWORTH, M. F. S.; PASSINGHAM, R. E.; NOBRE, A. C. Components of attentional set-switching. Experimental Psychology, v. 52, n.2, p. 83-98, 2005. 
RUZ, M.; LUPIÁÑEZ, J. A review of attentional capture: On its automaticity and sensitivity to endogenous control. Psicologica, v. 23, p. 283-309, 2002.

SHINTARO, F. Neural mechanisms of executive control by the prefrontal cortex. Neuroscience Research, v.39, p.147-165, 2001.

VAN DER LUBBE, R. O. VOGEL, R. O., POSTMA, A. Different effects of exogenous cues in a visual detection and discrimination task: Delayed Attention withdrawal and/or speeded motor inhibition? Journal of Cognitive Neuroscience, v.17, n.12, p. 1829-1840, 2005 .

VAN DER LUBBE, H. J. MARRTEN M. H, BEKKER, M. E.; POSTMA, A. Taskdependent exogenous cuing effects depend on cue modality. Psychophysiology, v.43, p.145-149, 2006.

YANTIS, S.; SERENCES, J. T. Cortical mechanisms of space-based and object-based attentional control. Current Opinion in Neurobiology, v.13, p.187-193, 2003. 
ANEXOS 


\section{ANEXO A}

\section{Questionário de Edinburgh (adaptado, 1971)}

NOME

IDADE

Você já teve alguma tendência a ser canhoto

Existe algum canhoto na sua família?

Indicar a preferência manual nas seguintes atividades assinalando + na coluna apropriada Quando a preferência for tão forte de modo a você nunca ser capaz de usar a outra mão assinale ++. Se não existir preferência, assinale + nas duas colunas.

\begin{tabular}{|l|l|l|}
\hline & Direita & Esquerda \\
\hline 1) Escrever & & \\
\hline 2) Desenhar & & \\
\hline 3) Jogar uma pedra & & \\
\hline 4) Usar uma tesoura & & \\
\hline 5) Usar um pente & & \\
\hline 6) Usar uma escova de dentes & & \\
\hline 7) Usar uma faca (sem o uso do garfo) & & \\
\hline 8) Usar uma colher & & \\
\hline 9) Usar um martelo & & \\
\hline 10)Usar uma chave de fendas & & \\
\hline 11)Usar uma raquete de tênis & & \\
\hline 12)Usar uma faca (com o garfo) & & \\
\hline 13)Usar uma vassoura (mão superior) & & \\
\hline 14)Usar um rodo (mão superior) & & \\
\hline 15)Acender um fósforo & & \\
\hline 16)Abrir um vidro com tampa (mão que segura a tampa) & & \\
\hline 17)Distribuir cartas & & \\
\hline 18)Enfiar a linha na agulha (mão que segura a linha) & & \\
\hline 19)Com que pé você prefere chutar? & & \\
\hline QUOCIENTE DE LATERALIDADE & & \\
\hline
\end{tabular}

QUOCIENTE DE LATERALIDADE

ACUIDADE VISUAL OD

OE BINOCULAR DOMINÂNCIA VISUAL APONTANDO FOTOGRAFANDO

TESTE DE DALTONISMO MEDICAMENTOS EM USO

SONO: HORAS DORMIDAS NA NOITE ANTERIOR PREFERÊNCIA HÁBITO DE JOGOS ELETRÔNICOS? OBS.: 
ANEXO B

\section{Teste de Acuidade Visual}

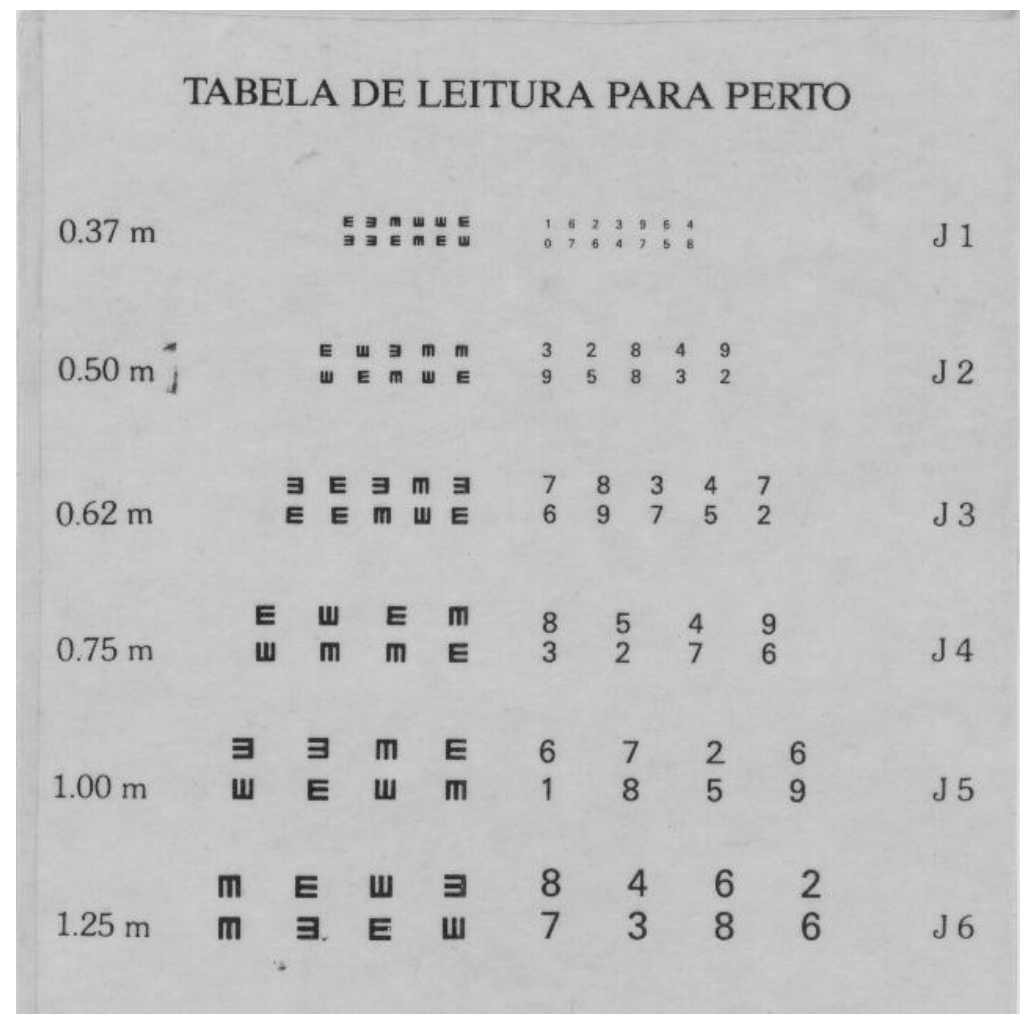

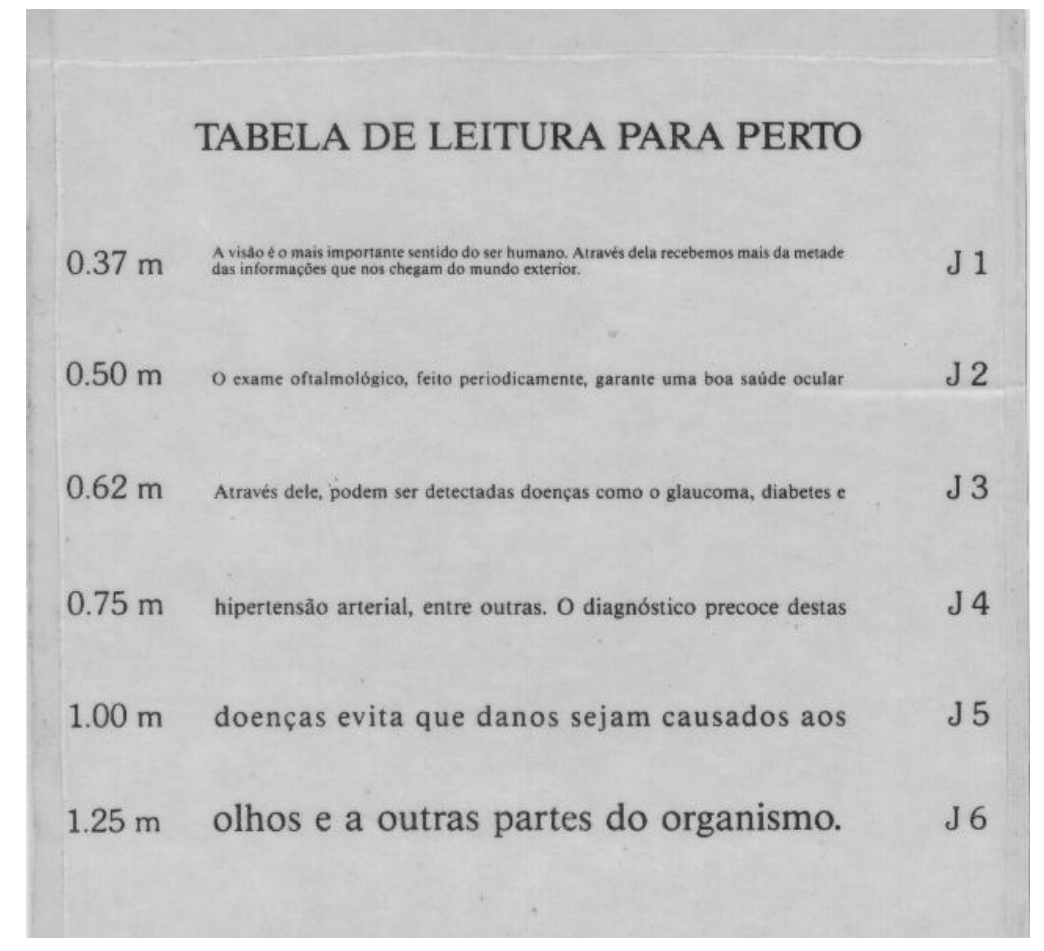




\section{ANEXO C \\ TERMO DE CONSENTIMENTO LIVRE E ESCLARECIDO}

Importância das características da situação estimulatória para os efeitos de um estímulo precedente visual

Você está sendo convidado(a) a participar do projeto de pesquisa acima citado. $O$ documento abaixo contém todas as informações necessárias sobre a pesquisa que estamos fazendo. Você poderá desistir da participação no projeto a qualquer momento, sem que isso lhe cause qualquer prejuizo. Agradecemos sua participação.

$\mathrm{Eu}$ profissão................ , residente e domiciliado na cidade de.................., portador da Cédula de identidade, RG ............................, e e inscrito no CPF/MF..........................nascido(a) em _ / / , abaixo assinado(a), concordo de livre e espontânea vontade em participar como voluntário(a) do estudo sobre o desempenho sensório-motor. Declaro que obtive todas as informações necessárias, bem como todos os eventuais esclarecimentos quanto às dúvidas por mim apresentadas.

Estou ciente que:

I) $\quad \mathrm{O}$ estudo se faz necessário para que se possam investigar os mecanismos atencionais. Investigaremos o efeito do estímulo precedente sobre o diferentes estímulos alvo e em que medida o uso de diferentes estratégias atencionais, a maneira como o organismo lida com a tarefa, são responsáveis pelos resultados.

II) Serão realizadas duas sessões, com duração de aproximadamente 20 minutos cada. $\mathrm{O}$ intervalo entre as sessões será de no mínimo 24 horas e no máximo Sete dias;

III) As sessões não representarão nenhum tipo de risco ou desconforto. Serão realizadas em uma sala com iluminação reduzida e algum isolamento acústico.

IV) Tenho a liberdade de desistir ou de interromper a colaboração neste estudo no momento em que desejar, sem necessidade de qualquer explicação;

V) Os resultados obtidos durante este estudo serão mantidos em sigilo, mas concordo que sejam divulgados em publicações científicas, desde que meus dados pessoais não sejam mencionados;

VI) Caso eu desejar, poderei pessoalmente tomar conhecimento dos resultados, ao final desta pesquisa

( ) Desejo conhecer os resultados desta pesquisa.

( ) Não desejo conhecer os resultados desta pesquisa.

São Paulo, $\quad 2006$

Voluntário (a):

Telefone para contato:

Testemunha 1 :

Nome / RG / Telefone

Testemunha 2 :

Nome / RG / Telefone

Responsável pelo Projeto:

Vivian de Alvarenga Guedes 







